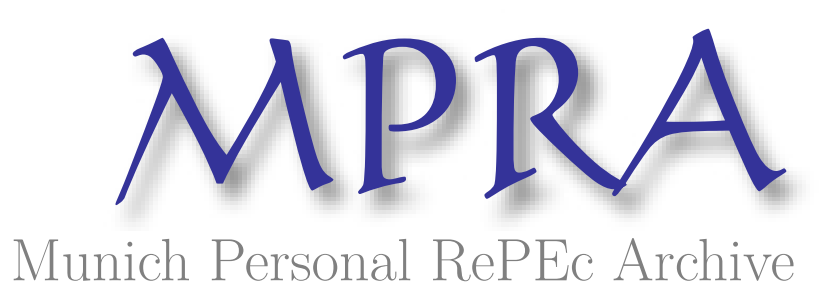

\title{
Money and Credit as Means of Payment: A New Monetarist Approach
}

Lotz, Sebastien and Zhang, Cathy

University of Paris 2, Purdue University

May 2015

Online at https://mpra.ub.uni-muenchen.de/64535/

MPRA Paper No. 64535, posted 25 May 2015 04:09 UTC 


\title{
Money and Credit as Means of Payment: A New Monetarist ApProach*
}

\author{
Sébastien Lotz ${ }^{\dagger}$ \\ LEMMA, University of Paris II
}

\author{
Cathy Zhang ${ }^{\ddagger}$ \\ Purdue University
}

May 2015

\begin{abstract}
This paper studies the choice of payment instruments in a simple model where both money and credit can be used as means of payment. We endogenize the acceptability of credit by allowing retailers to invest in a costly record-keeping technology. Our framework captures the two-sided market interaction between consumers and retailers, leading to strategic complementarities that can generate multiple steady-state equilibria. In addition, limited commitment makes debt contracts self-enforcing and yields an endogenous upper bound on credit use. So long as record-keeping is imperfect, money and credit coexist for a range of nominal interest rates. Our model captures the dependence of debt limits on monetary policy and explains how hold-up problems in technological adoption prevent retailers from accepting credit as consumers continue to coordinate on cash usage. With limited commitment, changes in monetary policy generate multiplier effects in the credit market due to complementarities between consumer borrowing and the adoption of credit by merchants.
\end{abstract}

Keywords: coexistence of money and credit, costly record-keeping, limited commitment JEL Classification Codes: D82, D83, E40, E50

\footnotetext{
*We are indebted to Guillaume Rocheteau for his feedback. This paper also benefitted from a discussion by Ed Nosal at the 2014 Boston Federal Reserve Payments Workshop and comments from Zach Bethune, Pedro GomisPorqueras, Tai-Wei Hu, Janet Jiang, Yiting Li, Scott Schuh, Tsz-Nga Wong, Chris Waller, Randy Wright and seminar and conference participants at Washington University in St. Louis, Federal Reserve Bank of Boston, Federal Reserve Bank of Chicago, Purdue University, Paris II, University of Queensland, U.C. Riverside, U.C. Irvine, University of Minnesota, University of Michigan, University of Southern California, Michigan State University, and Université de Lyon. An earlier draft of the paper first circulated in 2012 under the title "The Coexistence of Money and Credit as Means of Payment" and has been conducted as part of the project Labex MME-DII (ANR11-LBX-0023-01).

†Address: Université Panthéon-Assas-Paris II, 92 rue d'Assas, 75006 Paris, France. E-mail: lotz@u-paris2.fr.

${ }^{\ddagger}$ Address: Department of Economics, Krannert School of Management, Purdue University, 403 W. State St., West Lafayette, IN 47907, USA. E-mail: cmzhang@purdue.edu.
} 


\section{Introduction}

Technological improvements in electronic record-keeping have made credit cards as ubiquitous as cash as means of payment. In addition, much of the U.S. economy runs on debt, owed primarily to the development of credit cards that serve both as a payment instrument and a means for unsecured borrowing. ${ }^{1}$ According to the U.S. Survey of Consumer Finances (2007), nearly three-quarters of U.S. households own at least one credit card with approximately half of those households carrying outstanding balances on their accounts. Moreover, approximately $27 \%$ of U.S. households report simultaneously revolving credit card debt and holding sizeable amounts of low return liquid assets such as cash (Telyukova (2013)). Recent consumer payments data similarly suggest that while consumers are increasingly relying on credit cards for transactions, they are still not completely abandoning cash (Foster, Meijer, Schuh, and Zabek (2011), Briglevics and Schuh (2013)).

As consumers change the way they pay and businesses change the way they accept payments, it is increasingly important to understand how consumer demand affects merchant behavior and vice versa. In fact, the payment system is a classic example of a two-sided market where both consumers and firms must make choices that affect one other (Rysman (2009), BIS (2012)). This dynamic often generates complementarities and network externalities, a key feature of the retail payment market. ${ }^{2}$ These recent trends in the payments landscape raise many interesting and challenging questions for monetary theory and policy. Under what conditions can money and credit coexist? Can improved access to record-keeping drive out money? And in economies where both money and credit are used, how does policy and inflation affect credit market outcomes?

To answer these and related questions, we propose a unified model of money and credit that integrates several key insights from modern monetary theory, while still being analytically tractable and amenable to policy analysis. Instead of taking payment arrangements as given, our approach is in the tradition of New Monetarist Economics where the use of money and credit arise endogenously. ${ }^{3}$ To capture the two-sided nature of actual payment systems, our model focuses on the market interaction between consumers (buyers, or borrowers) and retailers (sellers, or lenders). The fundamental distinction between monetary and credit trades is that the former is settled on

\footnotetext{
${ }^{1}$ Unsecured credit refers to loans not tied to other assets or secured by the pledge of collateral, such as credit card loans. The Federal Reserve (2005) reports that credit card loans account for roughly half of all unsecured debt in the United States. Meanwhile, the number of payments made by general-purpose credit cards rose from 15.2 billion to 19.0 billion between 2003 and 2006 in the U.S. (Gerdes (2008)).

${ }^{2}$ Network externalities exist when the value of a good or service to a potential user increases with the number of other users using the same product. Credit cards are a classic example of a network good, where its adoption and use can be below the socially optimal level because consumers or firms do not internalize the benefit of their own use on others' use. For a discussion of the empirical issues, see Gowrisankaran and Stavins (2004) and Chakravorti (2010).

${ }^{3}$ A discussion of the New Monetarist approach is in Williamson and Wright (2010) and a textbook treatment is in Nosal and Rocheteau (2011), though the basic principles date back to Townsend (1987) and Wallace (1998).
} 
the spot and anonymous while the latter involves delayed settlement and record-keeping to keep track of transactions and enforce repayment. While many economies now feature the widespread adoption of both money and credit as a means of payment, getting money and credit to coexist in theory is a much more delicate issue. Indeed, across a wide class of models, there is a dichotomy between monetary and credit trades, a key insight from Kocherlakota (1998): so long as credit is feasible, there is no social role for money, and if money is valued, then credit cannot be sustained.

To generate a role for both money and credit, our model features two deep frictions motivating payment decisions: imperfect record-keeping and limited commitment. For credit to be feasible, we introduce a costly record-keeping technology that monitors and records transactions. As in Nosal and Rocheteau (2011, chapter 8), a seller who invests in this technology can accept an IOU from a buyer. ${ }^{4}$ Moreover, we follow a long tradition that views limited commitment as a key friction underlying credit market behavior. Since the use of credit hinges on trust, issues of repayment and enforcement are first order concerns. Due to limited commitment and enforcement, lenders cannot force borrowers to repay their debts. In order to motivate debt repayment, we assume that default by the borrower triggers a punishment that banishes agents from all future credit transactions (Alvarez and Jermann (2000), Kehoe and Levine (1993, 2001)). In that case, a defaulter can only trade with money. Consequently, debt contracts must be self-enforcing and the possibility of strategic default yields an endogenous upper bound on credit use. ${ }^{5}$

Our model generates three endogenous payment regimes: one with money only, one with credit only, and one with both money and credit. As a starting point, we first identify two necessary conditions to ensure individuals use both money and credit for transactions, a seemingly robust feature of actual payment arrangements that is quite difficult to reproduce in theory. In our model, both money and credit are used when some sellers (either exogenously or endogenously) accept both cash and credit while a subset only take cash. ${ }^{6}$ However, we show that imperfect record-keeping is a necessary but not sufficient ingredient for money and credit to coexist.

When the ability to enforce debt repayment is imperfect, moderate inflation is a second necessary ingredient for the coexistence of money and credit. The reason is that inflation now has two effects: a higher inflation rate lowers the rate of return on money and makes default more costly.

\footnotetext{
${ }^{4}$ Garcia-Swartz, Hahn, and Layne-Farrar (2006) find that the merchant's cost of a typical credit transaction in the U.S. is about seven times higher than their costs for accepting cash. This higher cost of accepting credit is borne by the merchant in the form of merchant fees that typically are not paid for explicitly by buyers.

${ }^{5}$ Not surprisingly, the main frictions in the model- costly record-keeping and limited commitment- are also key factors motivating the use of credit cards in practice. According to the Bank of Canada's Method of Payments survey, Fung, Huynh, and Sabetti (2012) report that the availability of record-keeping and the ability to make payments are among the primary determinants of credit card usage.

${ }^{6}$ Our approach is therefore similar to heterogeneous monitoring models where agents differ both ex-ante and ex-post, as in Cavalcanti and Wallace (1999) and Sanches and Williamson (2010).
} 
Consequently, inflation cannot be too high so that money is not valued, and inflation cannot be too low so that borrowers have an incentive to renege on their debts. ${ }^{7}$ Moreover, limited commitment provides a tight link between monetary policy and individual substitution patterns. By raising the cost of default and lowering the rate of return on money, higher inflation relaxes credit constraints and induces agents to shift from money to credit to finance their consumption. Hence when both money and credit are used, an exogenous change in policy that raises debt limits will not completely crowd out money. We show that this result holds so long as a fraction of sellers still take cash, thereby breaking the typical neutrality result that arises in economies with perfect access to record-keeping by sellers (Gu, Mattesini, and Wright (2014)).

Our model with endogenous debt limits and record-keeping underscores two important channels for monetary policy to affect credit market outcomes. Compared with an environment with perfect enforcement, we show that borrowing constraints depend on monetary policy and market fundamentals, which generates new insights about the relationship between policy and credit market behavior. The channel through which monetary policy affects macroeconomic outcomes is through buyers' portfolio holdings, sellers' investment decision, and the endogenous credit constraint. If sellers must invest ex-ante in a costly technology to record credit transactions, there are strategic complementarities between the seller's decision to invest and the buyer's ability to repay. When more sellers accept credit, the gain to buyers from borrowing increases, which relaxes the credit constraint. At the same time, an increase in the buyer's ability to repay raises the incentive to invest and hence the fraction of credit trades. This complementarity leads to feedback effects that can generate multiple steady-state equilibria, including outcomes where both money and credit are used. In terms of recent payment trends, this multiplier effect helps rationalize the rapid proliferation of unsecured credit beyond what can be explained by technological progress alone.

Moreover, this channel mimics the mechanism behind two-sided markets in actual payment systems: merchants want to accept credit cards that have many cardholders, and cardholders want cards that are accepted at many establishments. Just as in our model, the payment network benefits the merchant and the consumer jointly, leading to similar complementarities highlighted in the industrial organization literature (Chakravorti (2010)). At the same time, consumers may still coordinate on cash usage due to a hold-up problem in technological adoption. Since retailers do not receive the full surplus of technological adoption, they fail to internalize the total benefit of accepting credit. The choice of payment instruments will therefore depend on fundamentals, as well as history and social conventions.

\footnotetext{
${ }^{7}$ Inflation also relaxes debt limits in Berentsen, Camera, and Waller (2007) where credit is modeled as nominal bank loans. However, money remains the only means of payment since goods transactions remain private information. This channel is also present in other models of unsecured credit with limited enforcement, such as Sanches and Williamson (2010), Bethune, Rocheteau, and Rupert (2014), and Gu, Mattesini, and Wright (2014), among many others.
} 
The paper proceeds as follows. Section 1.1 discusses the related literature. Section 2 presents the benchmark environment with limited enforcement, and Section 3 determines equilibrium when an exogenous fraction of sellers accept credit. Section 4 characterizes payment regimes, and Section 5 endogenizes the acceptability of credit. In Section 6 , we discuss welfare and investigate the welfare effects of inflation. Finally, Section 7 closes with concluding remarks and posits some directions for future research.

\subsection{Related Literature}

Within modern monetary theory, there is a strong tradition of studying the coexistence of money and credit, such as Shi (1996), Kocherlakota and Wallace (1998), and Cavalcanti and Wallace (1999). More recently, there are several models featuring divisible money and centralized credit markets using the Lagos and Wright (2005) model, including Berentsen, Camera, and Waller (2007), Telyukova and Wright (2008), Sanches and Williamson (2010), Bethune, Rocheteau, and Rupert (2014), Gu, Mattesini, and Wright (2014), and Liu, Wang, and Wright (2014). However in all these approaches, only an exogenous subset of agents can use credit while the acceptability of credit is endogenous in this paper. Dong (2011) also models costly credit but focuses on the buyer's choice of credit. This distinction is important since heterogeneity on the buyer's side and not the seller's side implies that trades occur with money only or credit only, but not with both.

Our model of endogenous record-keeping is based on a version of the costly credit model in Nosal and Rocheteau (2011, chapter 8), though a key distinction is we derive an endogenous debt limit under limited commitment instead of assuming loan repayments are perfectly enforced. ${ }^{8}$ While some results on the existence of equilibrium go through, having limited commitment provides an important channel for monetary policy to affect equilibrium borrowing. This may be particularly relevant for making sense of recent consumer payments data as there is a sizeable fraction of individuals who are credit constrained and an important open question is how changes in monetary policy affect credit market outcomes. As just one example, our theory implies a fall in the nominal interest rate tightens credit constraints which generates a decline in consumer borrowing, even holding fixed the aggregate acceptability of credit by merchants. While this channel is absent under perfect enforcement, our model illustrates how having endogenous borrowing through limited commitment can offer a more comprehensive picture of credit market outcomes.

In a related setting but with complete access to record-keeping by sellers, Gu, Mattesini, and

\footnotetext{
${ }^{8}$ Our formalization is similar to Townsend (1989) and Williamson (1987)'s costly state verification assumption. More recently, a related idea appears in Lester, Postlewaite, and Wright (2012) where sellers must incur a fixed cost to authenticate and hence accept an asset for trade.
} 
Wright (2014) show that money is crowded out one for one when credit is also used. ${ }^{9}$ Moreover, since changes to the debt limit are neutral, their results imply that monetary policy has no effect on credit market behavior. Despite having similar topics and methods, our paper and $\mathrm{Gu}$, Mattesini, and Wright (2014) feature different environments and we highlight very different findings. While $\mathrm{Gu}$, Mattesini, and Wright (2014) consider a representative agent model with complete access to record-keeping by sellers, we consider heterogeneous record-keeping across sellers (both exogenously and endogenously). As we show, this distinction is critical for obtaining the coexistence of money and credit at the individual transaction level, a role for monetary policy to affect debt limits, and strategic complementarities between equilibrium borrowing and the aggregate availability of credit. Indeed, our model nests a version of the full record-keeping model of $\mathrm{Gu}$, Mattesini, and Wright (2014), in which case we obtain their neutrality result as a limiting case.

Finally, this paper relates with a growing strand in the industrial organization literature on payments that examines the costs and benefits of credit cards to network participants (Rochet and Tirole (2006), Wright (2011)). However, this literature abstracts from a critical distinction between money and credit transactions by ignoring the borrowing component of credit trades. An exception is Chakravorti and To (2007), which develops a theory of credit cards with delayed settlement. However since money is not modeled, the model cannot examine issues of coexistence and substitutability between cash and credit, which is a key contribution of the present paper.

\section{Environment}

Time is discrete and continues forever. There is a continuum [0,2] of infinitely lived agents, evenly divided between buyers (or consumers) and sellers (or retailers). Each period is divided into two sub-periods where economic activity will differ. In the first sub-period, agents meet pairwise and at random in a decentralized market, called the $D M$. Sellers can produce output, $q \in \mathbb{R}+$, but do not want to consume, while buyers want to consume but cannot produce. Agents' identities as buyers or sellers are permanent, exogenous, and determined at the beginning of the DM. In the second sub-period, trade occurs in a frictionless centralized market, called the $C M$, where all agents can consume a numéraire good, $x$, by supplying labor, $y$, using a linear technology $f(y)=y$.

Instantaneous utility functions for buyers, $\left(\mathcal{U}^{b}\right)$, and sellers, $\left(\mathcal{U}^{s}\right)$, are assumed to be separable

\footnotetext{
${ }^{9}$ Under an optimal trading mechanism, Hu, Kennan, and Wallace (2009) show that money and credit are not coessential in the Lagos and Wright (2005) model, so long as agents are not too impatient. Gu, Mattesini, and Wright (2014) adopt a similar model but with a more general preference structure and show that money and credit are not both needed for a class of trading mechanisms that only depend on the buyer's total wealth but not on portfolio composition. More recently, Araujo and $\mathrm{Hu}$ (2014) overturn these results and show that money and credit can be coessential in the Lagos and Wright (2005) model by having two rounds of DM trades. Since we do not adopt mechanism design, our analysis focuses instead on the coexistence, rather than coessentiality, of money and credit.
} 
Figure 1: Cost Function for Record-Keeping Technology

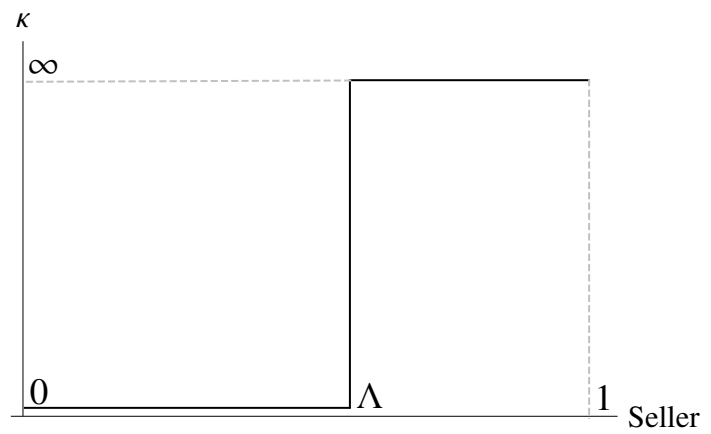

between sub-periods and linear in the CM:

$$
\begin{aligned}
& \mathcal{U}^{b}(q, x, y)=u(q)+x-y \\
& \mathcal{U}^{s}(q, x, y)=-c(q)+x-y .
\end{aligned}
$$

Functional forms for utility and cost functions are $C^{2}$ with $u^{\prime}>0, u^{\prime \prime}<0, c^{\prime}>0, c^{\prime \prime}>0$, $u(0)=c(0)=c^{\prime}(0)=0$, and $u^{\prime}(0)=\infty$. Also, let $q^{*} \equiv\left\{q: u^{\prime}\left(q^{*}\right)=c^{\prime}\left(q^{*}\right)\right\}$. All goods are perishable and agents discount the future between periods with a discount factor $\beta=\frac{1}{1+r} \in(0,1)$.

The only asset in the economy is fiat money, which is perfectly divisible, storable, and recognizable. Money $m_{t} \in \mathbb{R}_{+}$is valued at $\phi_{t}$, the price of money in terms of numéraire. Its aggregate stock in the economy, $M_{t}$, can grow or shrink each period at a constant gross rate $\gamma \equiv \frac{M_{t+1}}{M_{t}}$. Changes in the money supply are implemented through lump-sum transfers or taxes in the CM to buyers. In the latter case, we assume the government has enough enforcement in the CM so that agents will repay the lump-sum tax. ${ }^{10}$

There is a costly record-keeping technology that can record transactions and enforce repayment. At the beginning of the DM, sellers can invest to access this technology by paying a constant per period cost, $\kappa \geq 0$, in units of disutility. ${ }^{11}$ To simplify exposition, we assume for now that investment

\footnotetext{
${ }^{10}$ While the government can never observe agents' real balances, it has the authority to impose arbitrarily harsh penalties on agents who do not pay taxes when $\gamma<1$. Alternatively, Andolfatto (2013) considers an environment where the government's enforcement power is limited and the payment of lump-sum taxes is voluntary. Penalty for failing to pay taxes in the CM is permanent exclusion from the DM. Along these lines, Appendix B determines the size of the tax obligation that individuals are willing to honor voluntarily, in which case the Friedman rule is infeasible since it requires taxation and individuals may choose to renege on taxes if it is too high.

${ }^{11}$ The Bank of Canada's 2006 National Survey of Merchants reports that nearly all merchants accept cash while $92 \%$ accept both cash and credit cards (Arango and Taylor (2008)). The study also finds that record-keeping and other technological costs of accepting credit are incurred by the seller. For example, the ad valorem fee on credit card transactions is incurred by merchants, which in practice includes processing fees and interchange fees.
} 


\section{Decentralized \\ Retail Market}

(DM)

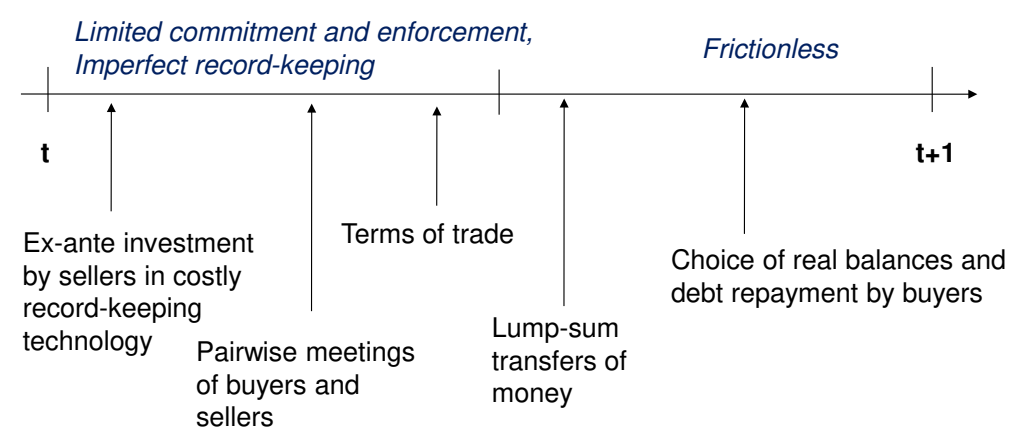

\section{Centralized}

Settlement Market

(CM)

in this technology is costless for a constant fraction $\Lambda \in[0,1]$ of sellers and infinitely costly for the remaining $1-\Lambda$ sellers, as in Figure 1. This implies the fraction of sellers with access to recordkeeping is exogenous and given by $\Lambda$. In Section 5 , we endogenize $\Lambda$ by considering a more general cost function where individual sellers have heterogenous costs of investing.

Contracts written in the DM can be repaid in the subsequent CM. Buyers can issue $b \in \mathbb{R}_{+}$units of one-period IOUs that we normalize to be worth one unit of the numéraire good. ${ }^{12}$ Since agents lack commitment, potential borrowers must be punished if they do not deliver on their promise to repay. We assume any default is publicly recorded by the record-keeping technology and triggers punishment that leads to permanent exclusion from the credit system. In that case, a borrower who defaults can only use money for all future transactions. ${ }^{13}$

Figure 2 summarizes the timing of events. At the beginning of the DM, a buyer matches with

\footnotetext{
${ }^{12}$ One interpretation of our model is that sellers with access to record-keeping can make loans directly to the buyer without interacting with an intermediary, such as a bank or credit card issuer. Hence, the seller and credit card issuer is modeled as a consolidated entity.

${ }^{13}$ The record-keeping technology detects default with probability one. Introducing imperfect monitoring where default is only detected probabilistically would all else equal decrease the cost of default and hence tighten credit limits. See e.g. the analysis in $\mathrm{Gu}$, Mattesini, and Wright (2014) and Bethune, Rocheteau, and Rupert (2014). In addition, while we assume that a defaulter is excluded from using credit but can still use money, one can also assume that punishment for default is permanent autarky. In Appendix B, we derive the debt limit assuming that punishment for default is permanent autarky and discuss the implications of this assumption.
} 
a seller with probability $\sigma$, where the buyer has $b \in \mathbb{R}+$ units of IOUs and $m \in \mathbb{R}+$ units of money, or equivalently, $z \equiv \phi m \in \mathbb{R}+$ units of real balances. Terms of trade are determined using a proportional bargaining rule. In the CM, buyers produce the numéraire good, redeem their loan, and acquire money, while sellers purchase the numéraire and can get their loan repaid.

\section{Equilibrium}

We focus on stationary equilibria where $\gamma \geq \beta$ and real balances are constant over time. Consequently, the rate of return on money is constant and equal to $\gamma^{-1}=\frac{\phi^{\prime}}{\phi}$. In what follows, variables with a prime denote next period's variables.

\subsection{Centralized Market Value Functions}

In the beginning of the CM, agents consume the numéraire good, supply labor, and readjust their portfolios. Let $W^{b}(z,-b)$ denote the value function of a buyer who holds $z \equiv \phi m$ units of real balances and has issued $b$ units of debt in the previous DM. Similarly, let $\widetilde{W}^{b}(z)$ denote the value function of a buyer with a recorded history of default and hence does not have access to credit.

The maximization problem for a buyer who enters the CM with portfolio $(z,-b)$ is

$$
\begin{gathered}
W^{b}(z,-b)=\max _{x, y, z^{\prime} \geq 0}\left\{x-y+\beta V^{b}\left(z^{\prime}\right)\right\} \\
\text { s.t. } x+b+\phi m^{\prime}=y+z+T,
\end{gathered}
$$

where $V^{b}\left(z^{\prime}\right)$ is the buyer's continuation value in the next DM and $T \equiv(\gamma-1) \phi M$ is the lumpsum transfer of money from the government (in units of numéraire). According to (2), the buyer finances his net consumption of the numéraire $(x-y)$, repayment of debt $(b)$, and next period's real balances $\left(\phi m^{\prime}\right)$ with his current real balances $(\phi m=z)$ and the lump-sum transfer $(T)$. Substituting $m^{\prime}=z^{\prime} / \phi^{\prime}$ into (2) and substituting $y$ into (1) yields

$$
W^{b}(z,-b)=z-b+T+\max _{z^{\prime} \geq 0}\left\{-\gamma z^{\prime}+\beta V^{b}\left(z^{\prime}\right)\right\} .
$$

The buyer's lifetime utility in the CM is the sum of his real balances net of any debt to be repaid, the lump-sum transfer from the government, and his continuation value at the beginning of the next DM net of the investment in real balances. Notice that $W^{b}$ is linear in the buyer's current portfolio: $W^{b}(z,-b)=z-b+W^{b}(0,0)$. In addition, the buyer's choice of real balances next period, $z^{\prime}$, is independent of his current real balances, $z$. 
Similarly, the value function of a buyer who defaults is

$$
\widetilde{W}^{b}(z)=z+T+\max _{z^{\prime} \geq 0}\left\{-\gamma z^{\prime}+\beta \widetilde{V}^{b}\left(z^{\prime}\right)\right\}
$$

where $\widetilde{V}^{b}\left(z^{\prime}\right)$ is the continuation value of a buyer who defaults and hence loses access to credit in the next DM.

Since sellers have no strict incentive to accumulate real balances in the DM, their CM value function is

$$
W^{s}(z, b)=z+b+\beta V^{s}(0)
$$

where $V^{s}(0)$ is the seller's value function at the beginning of the following DM.

\subsection{Terms of Trade}

Terms of trade in the DM are determined by Kalai (1977)'s proportional bargaining solution where the buyer receives a constant share $\theta \in(0,1)$ of the total surplus, while the seller gets the remaining share. Upon being matched, the buyer proposes to the seller a contract $(q, d, b)$, where $q$ is the quantity of output the seller transfers to the buyer, and $(d, b)$ are the transfers of real balances and IOUs, respectively, from the buyer to seller. ${ }^{14}$

In general, the terms of trade only depend on the total portfolio of the buyer and the payment accepted by the seller. Consider first a match where the seller accepts credit. Notice that the surplus of a buyer who gets $q$ for payment $d+b$ to the seller is $u(q)-d-b$, by the linearity of $W^{b}$. Similarly, the surplus of the seller is $-c(q)+d+b$. The bargaining problem is then

$$
\begin{gathered}
(q, d, b)=\arg \max _{q, d, b}\{u(q)-d-b\} \\
\text { s.t. }-c(q)+d+b=\frac{1-\theta}{\theta}[u(q)-d-b],
\end{gathered}
$$

\footnotetext{
${ }^{14}$ More generally, proportional bargaining guarantees that trade is pairwise Pareto efficient and has several desirable features that cannot be guaranteed with Nash bargaining, as discussed in Aruoba, Rocheteau, and Waller (2007). First, it guarantees the concavity of agents' value functions. Second, the proportional solution is monotonic and hence does not suffer from a shortcoming of Nash bargaining that an agent can end up with a lower individual surplus even if the size of the total surplus increases. While some of these technical complications can be dealt with, as in Lagos and Rocheteau (2008) and Lagos (2010), or avoided altogether by giving all the surplus to the buyer, here we want to give positive surplus to the seller since later on we endogenize the acceptability of credit and need to provide sellers some incentive to invest in the record-keeping technology. Moreover, there are also normative reasons to adopt Kalai bargaining. As recently shown by Bethune, Hu, and Rocheteau (2014), "not too tight" solvency constraints are socially optimal under proportional bargaining but cannot be justified on normative grounds with Nash bargaining. In any case, we also work out the model with generalized Nash bargaining and show in Appendix $\mathrm{C}$ that our main coexistence results go through, though some existence conditions and results related to efficiency slightly differ.
} 


$$
\begin{gathered}
d \in[0, z], \\
b \in[0, \bar{b}] .
\end{gathered}
$$

According to (4) - (7), the buyer's offer maximizes his trade surplus such that (i) the seller's payoff is a constant share $\frac{1-\theta}{\theta}$ of the buyer's payoff, (ii) the buyer cannot transfer more money than he has, and (iii) the buyer cannot borrow more than he can repay. Condition (6) is a feasibility constraint on the amount the buyer can transfer to the seller, while condition (7) is the buyer's incentive constraint that motivates voluntary debt repayment. The threshold $\bar{b}$ is an equilibrium object and represents the endogenous borrowing limit faced by the buyer, which is taken as given in the bargaining problem. Combining (6) and (7) results in the payment constraint

$$
d+b \leq z+\bar{b}
$$

which says the total payment to the seller, $d+b$, cannot exceed the buyer's payment capacity, $z+\bar{b}$. The bargaining solution depends on whether or not the payment constraint binds. If (8) does not bind, then the buyer has sufficient wealth to purchase the first best level of output, $q^{*}$. In that case, payment to the seller will be exactly

$$
d+b=(1-\theta) u\left(q^{*}\right)+\theta c\left(q^{*}\right) .
$$

If (8) binds, the buyer does not have enough payment capacity and will borrow up to his credit limit and pay the rest with any cash on hand:

$$
z+\bar{b}=(1-\theta) u\left(q^{c}\right)+\theta c\left(q^{c}\right)
$$

where $q^{c} \equiv q(z+\bar{b})<q^{*}$.

If the seller does not have access to record-keeping, credit cannot be used. In that case, the bargaining problem is described by (4) - (6) but with $b=\bar{b}=0$. If $z \geq(1-\theta) u\left(q^{*}\right)+\theta c\left(q^{*}\right)$, the buyer is unconstrained and has enough liquid wealth to purchase $q^{*}$. Otherwise, the buyer just hands over his real balances,

$$
z=(1-\theta) u(q)+\theta c(q),
$$

where $q \equiv q(z)<q^{*}$. The bargaining solution if the buyer defaults is similar to (10), where $q$ is replaced with $\widetilde{q}$ and the real balances of a buyer who defaults is $\widetilde{z}=(1-\theta) u(\widetilde{q})+\theta c(\widetilde{q})$ if $\widetilde{z}<(1-\theta) c\left(q^{*}\right)+\theta u\left(q^{*}\right)$ and $\widetilde{z}=(1-\theta) c\left(q^{*}\right)+\theta u\left(q^{*}\right)$ otherwise. 


\subsection{Decentralized Market Value Functions}

We next describe agents' value functions in the DM. After simplification, the expected lifetime utility of a buyer with no history of default who holds $z$ units of real balances at the beginning of the period is:

$$
V^{b}(z)=\sigma \theta(1-\Lambda)[u(q)-c(q)]+\sigma \theta \Lambda\left[u\left(q^{c}\right)-c\left(q^{c}\right)\right]+z+W^{b}(0,0),
$$

where we have used the bargaining solution and the fact that the buyer will never accumulate more real balances than he would spend in the DM. According to (11), a buyer in the DM is matched with a seller who does not have access to record-keeping with probability $\sigma(1-\Lambda)$, receives $\theta$ of the match surplus, $u(q)-c(q)$, and can only pay with money. With probability $\sigma \Lambda$, a buyer matches with a seller with access to record-keeping, in which case he gets $\theta$ of the match surplus, $u\left(q^{c}\right)-c\left(q^{c}\right)$, and can pay with both money and credit. The last two terms result from the linearity of $W^{b}$ and is the value of proceeding to the CM with one's portfolio intact.

Similarly, the expected lifetime utility of a buyer who defaults is

$$
\widetilde{V}^{b}(z)=\sigma \theta[u(\widetilde{q})-c(\widetilde{q})]+z+\widetilde{W}^{b}(0),
$$

which reflects the fact that a buyer who defaults loses access to credit and can only consume $\widetilde{q}$ by trading with money. However if money is not valued, then a buyer who defaults cannot trade at all in the DM.

\subsection{Optimal Portfolio Choice}

We now turn to the buyer's choice of real balances. Substituting $V^{b}(z)$ from (11) into (3), the choice of real balances for a buyer with access to credit solves

$$
\max _{z \geqslant 0}\{-i z+\sigma(1-\Lambda) \theta S(z)+\sigma \Lambda \theta S(z+\bar{b})\}
$$

where $S(\cdot) \equiv u[q(\cdot)]-c[q(\cdot)]$ is the total trade surplus in a bilateral match and $i \equiv \frac{\gamma-\beta}{\beta}$ is the nominal interest rate on an illiquid bond and represents the cost of holding real balances. According to (12), the buyer's choice of real balances maximizes his expected surplus in the DM net of the cost of holding money. Since the objective function (12) is continuous and maximizes over a compact set, a solution exists. In Appendix A, we show that (12) is a concave problem. Accordingly, the buyer's 
choice of real balances, $z \geq 0$, solves

$$
-i+\sigma \theta(1-\Lambda) S^{\prime}(z)+\sigma \theta \Lambda S^{\prime}(z+\bar{b}) \leq 0
$$

where (13) is satisfied with equality if $z>0$ and $S^{\prime}(\cdot)=\frac{u^{\prime}[q(\cdot)]-c^{\prime}[q(\cdot)]}{\theta c^{\prime}[q(\cdot)]+(1-\theta) u^{\prime}[q(\cdot)]}$ represents the liquidity premium. Using a similar line of reasoning, the choice of real balances for a buyer who defaults and hence loses access to credit, $\widetilde{z} \geq 0$, solves

$$
-i+\sigma \theta S^{\prime}(\widetilde{z}) \leq 0
$$

where (14) is satisfied with equality if $\widetilde{z}>0$.

Notice that when all sellers have access to record-keeping $(\Lambda=1)$ and money is valued, $(13)$ and (14) at equality implies that a buyer with access to credit chooses his real balances so that his total wealth is the same as a buyer who defaults, or $z+\bar{b}=\widetilde{z}$. Intuitively, a buyer who repays his debt faces the same tradeoff at the margin as a buyer who defaults. Moreover, when $\Lambda=1$, any change in the debt limit (either exogenous or endogenous) is offset by a change of the same magnitude in real balances. To see this when $\bar{b}$ is exogenous, differentiate (13) to obtain

$$
\frac{d z}{d \bar{b}}=-\left[1+\frac{(1-\Lambda) S^{\prime \prime}(z)}{\Lambda S^{\prime \prime}(z+\bar{b})}\right]^{-1} \in[-1,0) .
$$

When $\Lambda=1, \frac{d z}{d \bar{b}}=-1$, in which case any increase in the debt limit leaves the buyer's total wealth unchanged. Importantly, this result does not hold more generally for our model with $\Lambda \in(0,1)$ due to the subset of trades that do not require credit. We give a more formal treatment of this outcome in Section 4.3.1 when characterizing an equilibrium with both money and credit.

Finally, notice that under perfect enforcement, buyers are never constrained by the limit $b \leq \bar{b}$ and can borrow as much as they want to finance the first best, $q^{*}$. When money is valued, the third term on the left side of (13) goes to zero since $u^{\prime}\left(q^{*}\right)=c^{\prime}\left(q^{*}\right)$. In that case, the second term on the left side of (13) is increasing with $\Lambda$ so that an increase in $\Lambda$ decreases output, $q(z)$, and hence the buyer's real balances, $z$.

\section{Endogenous Credit Limits}

When the government's ability to enforce repayment is limited, borrowers may have an incentive to renege on their debt obligations. To support trade in a credit economy, we assume punishment for default entails permanent exclusion from the credit system. In that case, a borrower who defaults 
can only use money for all future transactions.

The equilibrium credit limit, $\bar{b}$, is determined so that the buyer voluntarily repays his debt. The buyer's incentive compatibility constraint for voluntary debt repayment is

$$
W^{b}(z,-b) \geqslant \widetilde{W}^{b}(z)
$$

where $W^{b}(z,-b)$ is the value function of a buyer who repays his debt at the beginning of the CM, and $\widetilde{W}^{b}(z)$ is the value function of a buyer who defaults. Hence, a buyer chooses to repay his debt if his lifetime utility if he does not default exceeds his lifetime utility if he reneges, or

$$
-b+W^{b}(z, 0) \geq \widetilde{W}^{b}(z)
$$

According to (15), a buyer who honors his debt obligation repays his debt, $-b$, and enters the CM with $z$ units of real balances and access to future credit, while a buyer who defaults enters the CM with a history of recorded default and hence loses access to future credit. By the linearity of $W^{b}$ and $\widetilde{W}^{b},(15)$ can be rewritten as

$$
b \leq \bar{b} \equiv W^{b}(0,0)-\widetilde{W}^{b}(0)
$$

where $\bar{b}$ is the endogenous upper bound on credit. According to (16), the amount borrowed can be no larger than the expected cost of default, which is the difference between the lifetime utility of a buyer with access to credit and the lifetime utility of a buyer permanently excluded from using credit. Notice that due to absence of wealth effects, the debt limit $\bar{b}$ is independent of the buyer's real balances held in the beginning of the CM.

Lemma 1. An equilibrium debt limit, $\bar{b}$, solves

$$
r \bar{b}=\max _{z \geq 0}\{-i z+\sigma \theta[(1-\Lambda) S(z)+\Lambda S(z+\bar{b})]\}-\max _{\widetilde{z} \geq 0}\{-i \widetilde{z}+\sigma \theta S(\widetilde{z})\} \equiv \Omega(\bar{b}) .
$$

The left side of (17), r $\bar{b}$, represents the return from borrowing a loan of size $\bar{b}$. The right side, $\Omega(\bar{b})$, is the flow cost of default, which equals the surplus from not having access to credit. According to (17), a solution to the debt limit is a fixed point of $r \bar{b}=\Omega(\bar{b})$.

Definition 1. Given $\Lambda$, a stationary equilibrium is a list $\left(q, q^{c}, z, \widetilde{z}, \bar{b}\right)$ that solves (9), (10), (13), (14), and (17). Equilibrium is said to be monetary if $\phi>0$ and non-monetary if $\phi=0$.

To characterize an equilibrium with credit, we start by establishing some key properties of the flow cost of default, $\Omega(\bar{b})$. Notice that the value of $\Omega(\bar{b})$ depends on the buyer's off-equilibrium 
choice of real balances in the event of default, $\widetilde{z}$, which itself depends on the value of money, $\phi$. We therefore distinguish two cases for the flow cost of default: (1) when money is not valued $(\phi=0)$ and (2) when money is valued $(\phi>0)$.

When money is not valued and hence $\phi m=z=0$, a buyer rationally anticipates that punishment for default is permanent autarky. Since defaulters will not be able to trade in the future, $\widetilde{z}=0$ in steady state. Accordingly, the right side of (17) when money is not valued is given by

$$
\left.\Omega(\bar{b})\right|_{\phi=0} \equiv \sigma \Lambda \theta S(\bar{b})
$$

When money is valued and $\phi m=z>0$, a buyer anticipates being able to trade with money in the future. In turn, $\widetilde{z}>0$ solves (14) at equality, and the flow cost of default is given by

$$
\left.\Omega(\bar{b})\right|_{\phi>0} \equiv \max _{z>0}\{-i z+\sigma \theta[(1-\Lambda) S(z)+\Lambda S(z+\bar{b})]\}-\max _{\widetilde{z}>0}\{-i \widetilde{z}+\sigma \theta S(\widetilde{z})\}
$$

To describe the properties of $\left.\Omega(\bar{b})\right|_{\phi=0}$ and $\left.\Omega(\bar{b})\right|_{\phi>0}$, it is useful to define a critical value for the debt limit. Consider a meeting where the seller has access to record-keeping. Suppose $i>0$ and define $\bar{b}_{1}$ as the threshold for the debt limit, above which agents can finance the first-best with credit. From the bargaining solution, the buyer has sufficient wealth to obtain $q^{*}$ when $(1-\theta) u\left(q^{*}\right)+\theta c\left(q^{*}\right) \leq z+\bar{b}$. If money is not valued, then $\bar{b}_{1}=(1-\theta) u\left(q^{*}\right)+\theta c\left(q^{*}\right)$. If money is valued, then (13) is satisfied with equality, and the threshold for the debt limit, above which buyers can obtain the first-best is given by $\bar{b}_{1}-\bar{z}$ where $\bar{z}$ solves

$$
i=\sigma \theta(1-\Lambda) S^{\prime}(\bar{z})
$$

In that case, $q^{c}=q^{*}$ if $\bar{b} \geq \bar{b}_{1}-\bar{z}$ and $q^{c}<q^{*}$ otherwise.

We now summarize some key properties of $\left.\Omega(\bar{b})\right|_{\phi=0}$ and $\left.\Omega(\bar{b})\right|_{\phi>0}$ in the lemma below. In Section 4.3.1, we consider a special case of the model with perfect record-keeping $(\Lambda=1)$, which has some qualitatively different properties from the model with imperfect record-keeping studied below.

Lemma 2. Given $\Lambda \in(0,1)$ and $i>0$, the correspondence $\Omega(\bar{b})$ has the following properties.

1. When money is not valued, $\left.\Omega(\bar{b})\right|_{\phi=0}$ is such that

(a) $\left.\Omega(0)\right|_{\phi=0}=0$

(b) $\left.\Omega^{\prime}(0)\right|_{\phi=0}=\frac{\sigma \Lambda \theta}{1-\theta}>0$, 
Figure 3: Flow Cost of Default, $\Omega(\bar{b})$, when $\Lambda \in(0,1)$

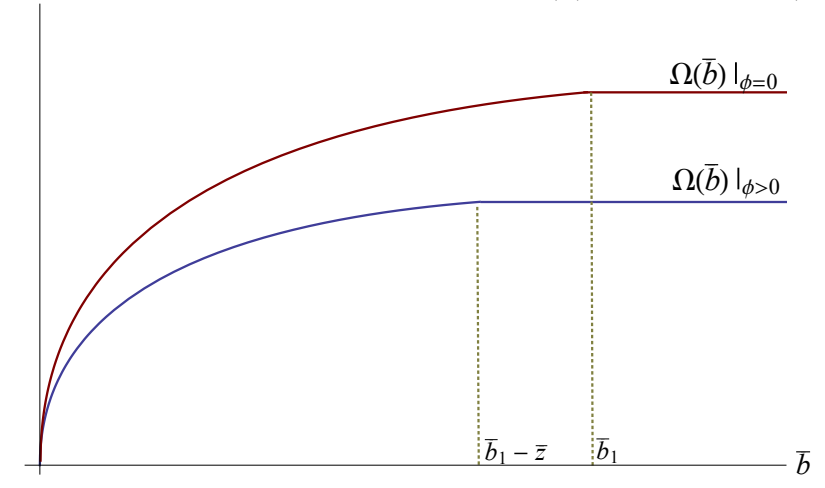

(c) $\left.\Omega^{\prime}(\bar{b})\right|_{\phi=0}= \begin{cases}\sigma \theta \Lambda S^{\prime}(\bar{b})>0 & \text { if } \bar{b}<\bar{b}_{1} \\ 0 & \text { if } \bar{b} \geq \bar{b}_{1},\end{cases}$

(d) $\left.\Omega(\bar{b})\right|_{\phi=0}$ is strictly increasing and concave for all $\bar{b}<\bar{b}_{1}$ and is constant at $\sigma \theta \Lambda S^{*}$ where $S^{*} \equiv u\left(q^{*}\right)-c\left(q^{*}\right)$ otherwise.

2. When money is valued, $\left.\Omega(\bar{b})\right|_{\phi>0}$ is such that

(a) $\left.\Omega(0)\right|_{\phi>0}=0$

(b) $\left.\Omega^{\prime}(0)\right|_{\phi>0}=i \Lambda>0$,

(c) $\left.\Omega^{\prime}(\bar{b})\right|_{\phi>0}= \begin{cases}\sigma \theta \Lambda S^{\prime}(z+\bar{b})>0 & \text { if } \bar{b}<\bar{b}_{1}-\bar{z} \\ 0 & \text { if } \bar{b} \geq \bar{b}_{1}-\bar{z},\end{cases}$

(d) $\left.\Omega(\bar{b})\right|_{\phi>0}$ is strictly increasing and concave for all $\bar{b}<\bar{b}_{1}-\bar{z}$ and is constant at $\sigma \theta \Lambda S^{*}$ otherwise.

Figure 3 illustrates the key properties of the flow cost of default from Lemma 2. The top curve is $\left.\Omega(\bar{b})\right|_{\phi=0}$ while the bottom curve is $\left.\Omega(\bar{b})\right|_{\phi>0}$. With Kalai bargaining, both curves are continuous, increasing, and concave. Consider first $\left.\Omega(\bar{b})\right|_{\phi=0}$ where money is not valued. When $\bar{b}<\bar{b}_{1}$, credit is tight and the flow cost of default increases with the size of the loan. Since a higher credit line makes default more tempting, a harsher punishment is needed to ensure credit is incentive feasible. When $\bar{b} \geq \bar{b}_{1}$, credit alone is sufficient to finance the first best, and the flow cost of default becomes constant and equal to $\sigma \theta \Lambda S^{*}$. Similar explanations apply for $\left.\Omega(\bar{b})\right|_{\phi>0}$, except the threshold for the debt limit above which the first-best can be attained is less stringent and given by $\bar{b}_{1}-\bar{z}$. 
From Lemma 2, notice when $i<\frac{\sigma \theta}{1-\theta}$, the slope of $\left.\Omega(\bar{b})\right|_{\phi>0}$ at $\bar{b}=0$, which is $\sigma \theta \Lambda S^{\prime}(z)=i \Lambda$, is strictly less than the slope of $\left.\Omega(\bar{b})\right|_{\phi=0}$ at $\bar{b}=0$, which is $\sigma \theta \Lambda S^{\prime}(0)=\frac{\sigma \Lambda \theta}{1-\theta}$. Moreover, $\left.\Omega^{\prime}(\bar{b})\right|_{\phi>0}<$ $\left.\Omega^{\prime}(\bar{b})\right|_{\phi=0}$ for all $\bar{b}$ whenever the credit constraint binds. Hence in Figure 3 , the curve $\left.\Omega(\bar{b})\right|_{\phi>0}$ lies strictly below the curve $\left.\Omega(\bar{b})\right|_{\phi=0}$. Intuitively, default is less costly at the margin when money is valued than when money is not valued since in the former, the buyer can still use money for future transactions.

We now turn to characterizing three types of steady-state equilibria that can arise in the model: (i) a pure monetary equilibrium, (ii) a pure credit equilibrium, and (iii) a money and credit equilibrium.

\subsection{Pure Monetary Equilibrium}

We start by considering a benchmark pure monetary equilibrium where money is valued and credit is not used. This type of outcome arises in environments with limited commitment and no access to record-keeping $(\Lambda=0)$, as in the New Monetarist models of Lagos and Wright (2005) and Rocheteau and Wright (2005). Not surprisingly, this outcome also arises in our environment with limited commitment and imperfect record-keeping, that is for any $\Lambda \in[0,1]$, so long as inflation is not too high.

First, money is valued given there is no credit if and only if

$$
i<\frac{\sigma \theta}{1-\theta} \equiv \bar{i}
$$

where we have used the fact that $S(z)$ is a concave function and $S^{\prime}(0)=\frac{1}{1-\theta}$. The critical value, $\bar{i}$, is the upper bound on the nominal interest rate, above which money is no longer valued. ${ }^{15}$

Since an equilibrium without credit always exists and is self fulfilling, a necessary and sufficient condition for a pure monetary equilibrium is $i<\bar{i}$. Since this condition is independent of $\Lambda$, the existence of a pure monetary equilibrium is invariant to access to record keeping by sellers.

\subsection{Pure Credit Equilibrium}

In a pure credit equilibrium, money is not valued while credit is used. When money is not valued, the debt limit $\bar{b}$ solves

$$
r \bar{b}=\left.\sigma \theta \Lambda S(\bar{b}) \equiv \Omega(\bar{b})\right|_{\phi=0} .
$$

\footnotetext{
${ }^{15}$ In a monetary model where $z$ depends on $q$, one must also check if there are corner solutions, i.e. $z=0$, which may not ruled out even with the Inada condition $u^{\prime}(0)=\infty$. Why would buyers ever choose $z=0$ ? While the buyer's marginal utility is infinite at $z=0$, marginal cost can be infinite as well. Here, marginal cost is given by the term $\frac{d z}{d q}=\theta c^{\prime}(q)+(1-\theta) u^{\prime}(q)$. By the envelope theorem, the term $\frac{u^{\prime}(q)-c^{\prime}(q)}{\theta c^{\prime}(q)+(1-\theta) u^{\prime}(q)}$ at $z=0$ becomes $\frac{1}{1-\theta}$.
} 
A necessary condition for credit is that the slope of $r \bar{b}$ is less than the slope of $\left.\Omega(\bar{b})\right|_{\phi=0}$ at $\bar{b}=0$, or

$$
r<\frac{\sigma \Lambda \theta}{1-\theta}
$$

which says that agents have to be patient enough to sustain voluntary debt repayment. Hence when the fraction of sellers accepting credit is exogenous, there exists a threshold for the fraction of credit trades, below which $\bar{b}=0$. From (19), credit is feasible given money is not valued if

$$
\Lambda>\frac{r(1-\theta)}{\sigma \theta} \equiv \bar{\Lambda}
$$

Since there always exists an equilibrium where money is not valued, a necessary condition for a pure credit equilibrium is $\Lambda>\bar{\Lambda}$.

Figure 4: Pure Credit Equilibrium when $\Lambda>\bar{\Lambda}$

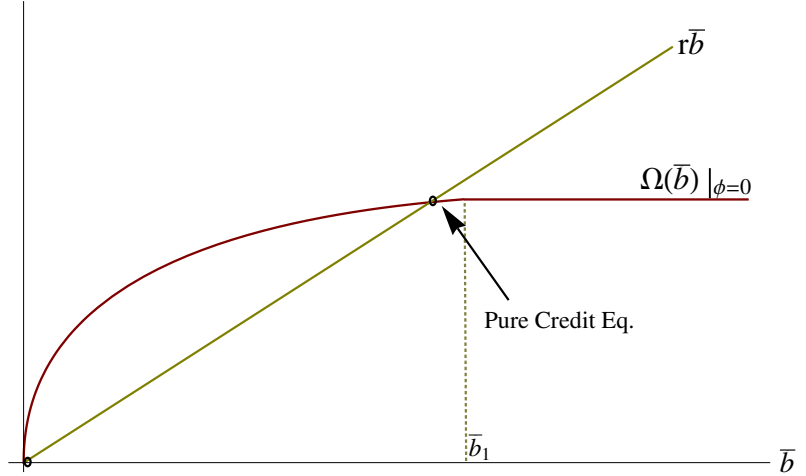

Figure 5: No Credit Equilibrium when $\Lambda \leq \bar{\Lambda}$

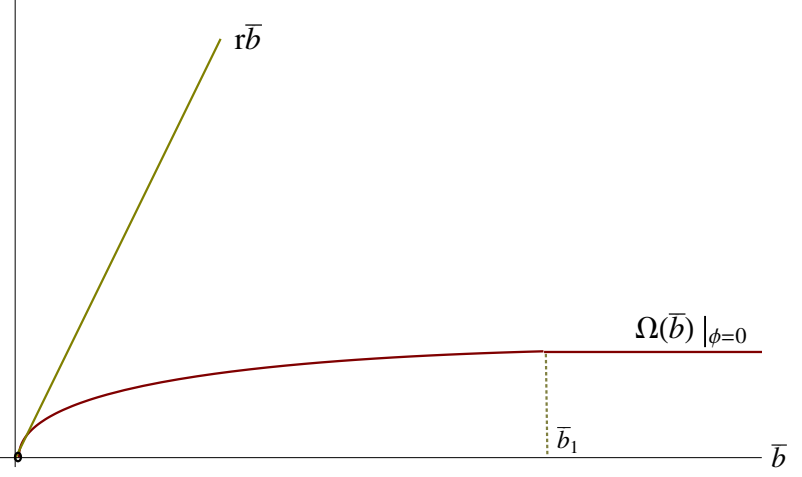

Figure 4 shows credit is feasible if $\Lambda>\bar{\Lambda}$ so that $\left.\Omega(\bar{b})\right|_{\phi=0}$ intersects with $r \bar{b}$ from above. In addition, the line $r \bar{b}$ rotates to the right as agents become more patient, which relaxes the debt limit. Even when enforcement is limited, credit alone can sustain the first best as long as agents care enough about the future, that is if

$$
r \leq \frac{\sigma \Lambda \theta\left[u\left(q^{*}\right)-c\left(q^{*}\right)\right]}{(1-\theta) u\left(q^{*}\right)+\theta c\left(q^{*}\right)} \equiv r^{*}
$$

In contrast, credit is not incentive feasible when $\Lambda \leq \bar{\Lambda}$ as in Figure 5. Notice in both Figures 4 and 5 , there is an equilibrium without credit since $\bar{b}=0$ is always a solution to (17). This captures the idea that an equilibrium without credit is self-fulfilling and can arise under the expectation that borrowers will not repay their debts in the future.

Notice when $\Lambda \leq \bar{\Lambda}$ and $i<\bar{i}$, credit is not feasible while money is valued. On the other hand, 
when $\Lambda>\bar{\Lambda}$ and $i \geq \bar{i}$, credit is feasible while money is too costly to hold. Is it possible then to have an equilibrium with both money and credit? We show formally in the next subsection the answer is yes, so long as record-keeping is imperfect and inflation is in an intermediate range.

\subsection{Money and Credit Equilibrium}

In an equilibrium with both money and credit, $\bar{b}>0$ and $z>0$. We first derive existence conditions for a money and credit equilibrium when $\Lambda \in(0,1)$, and then turn to a very special case of the model when $\Lambda=1$. In either case, we verify that two conditions are satisfied for a money and credit equilibrium to exist: (1) credit is incentive feasible given money is valued and (2) money is valued given a debt limit.

To describe a monetary equilibrium with credit, we further characterize $\left.\Omega(\bar{b})\right|_{\phi>0}$ by establishing the existence of a critical debt limit above which money is no longer valued. If it exists, it is the value $\bar{b}_{0}$ that solves (13) at equality with $z=0$ :

$$
i=\frac{\sigma(1-\Lambda) \theta}{1-\theta}+\sigma \Lambda \theta S^{\prime}\left(\bar{b}_{0}\right)
$$

For (20) to be well defined, $\bar{b}_{0}$ must be non-negative and finite. Accordingly, the threshold $\bar{b}_{0}$ exists if and only if $i \geq \widehat{i} \equiv \frac{\sigma(1-\Lambda) \theta}{1-\theta}$. Notice that when $\Lambda=1, \bar{b}_{0}$ exists for all $i>0$.

Lemma 3. Given $\Lambda \in(0,1)$ and $i>0$, the following outcomes are possible.

1. Suppose $i<\widehat{i}$. Then, $z>0$ for all $\bar{b} \in[0, \infty)$.

2. Suppose $i \geq \widehat{i}$. Then, $z>0$ for all $\bar{b} \in\left[0, \bar{b}_{0}\right)$ and $z=0$ otherwise.

According to Lemma $3, i<\widehat{i}$ implies money is valued for any debt limit, and $i \geq \hat{i}$ implies there exists a critical debt limit above which money is not valued. Notice when $i=\widehat{i}_{i} \bar{b}_{0}=\bar{b}_{1}$, in which case money is valued for all $\bar{b}<\bar{b}_{1}$. Intuitively, when $i \geq \widehat{i}$ and $\bar{b} \geq \bar{b}_{0}$, inflation can be high enough that credit starts to crowd out money for transactions. Even though a subset of sellers always accept cash, buyers may choose not to hold money if credit is sufficiently abundant. Given $i>0$, notice also that whenever money is valued, $q<q^{*}$ and $q^{c}<q^{*}$. As is typically the case in this class of models, buyers are liquidity constrained in any monetary equilibrium except possibly at the Friedman rule. At the Friedman rule, there is a unique equilibrium with positively valued money. In that equilibrium, credit limits cannot be sustained.

We now turn to verifying the conditions for a money and credit equilibrium to exist. First, given money is valued, there is a positive debt limit if the slope of $\left.\Omega(\bar{b})\right|_{\phi>0}$ at $\bar{b}=0, \sigma \theta \Lambda S^{\prime}(z)$, is 
greater than the slope of $r \bar{b}$, or

$$
i \Lambda>r,
$$

where we have used the fact that when money is valued, $i=\sigma \theta S^{\prime}(z)$ at $\bar{b}=0$. As a result, a necessary condition for credit to be feasible given valued money is

$$
i>\frac{r}{\Lambda} \equiv \underline{i}
$$

The critical value $\underline{i}$ is the lower bound on the nominal interest rate, above which credit is feasible when money is valued. Intuitively, condition (21) says that the cost of holding money cannot be too low so that buyers would prefer to renege on repayment. At the same time, buyers also have to be patient enough to care about the possibility of future punishment.

Second, given $\bar{b}$, there is an interior solution for real balances if and only if

$$
i<\frac{\sigma(1-\Lambda) \theta}{1-\theta}+\sigma \Lambda \theta S^{\prime}[\bar{b}(i, \Lambda)]
$$

where $\bar{b}(i, \Lambda)$ implicitly defines $\bar{b}$ as a function of $i$ and $\Lambda$. Consequently, money is valued given a positive debt limit if

$$
i<\widetilde{i}
$$

where $\widetilde{i}$ solves

$$
\widetilde{i}=\frac{\sigma(1-\Lambda) \theta}{1-\theta}+\sigma \Lambda \theta S^{\prime}[\bar{b}(\widetilde{i}, \Lambda)] .
$$

Consequently, a necessary condition for a money and credit equilibrium to exist is $i \in(\underline{i}, \widetilde{i})$ and $\Lambda>\bar{\Lambda}$.

Figures 6 and 7 depict two examples of a money and credit equilibrium when $i<\widehat{i}$ and $i>\widehat{i}$, respectively. In both cases, a money and credit equilibrium exists if $\Lambda \in(\bar{\Lambda}, 1)$ and $i \in(\underline{i}, \widetilde{i})$. Recall that $\Lambda>\bar{\Lambda}$ is a necessary condition for a credit to be feasible. In order for there to be credit with valued money, the condition $i>\underline{i}$ implies that $\left.\Omega(\bar{b})\right|_{\phi>0}$ must intersect with $r \bar{b}$ from above. Moreover, since $\widetilde{i}<\bar{i}$, the necessary and sufficient condition for a pure monetary equilibrium, $i<\bar{i}$, is always satisfied whenever $i<\widetilde{i}$. Consequently, whenever $\Lambda \in(\bar{\Lambda}, 1)$ and $i \in(\underline{i}, \widetilde{i})$ so that a money and credit equilibrium exists, there also exists a pure monetary equilibrium and pure credit equilibrium. 
Figure 6: Money and Credit Equilibrium when $\Lambda \in(\bar{\Lambda}, 1), i \in(\underline{i}, \widetilde{i})$, and $i<\widehat{i}$

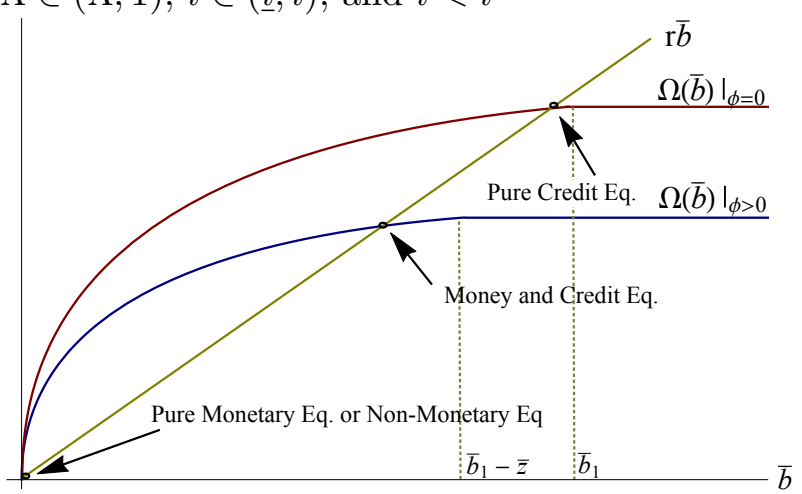

Figure 7: Money and Credit Equilibrium when $\Lambda \in(\bar{\Lambda}, 1), i \in(\underline{i}, \widetilde{i})$, and $i>\widehat{i}$

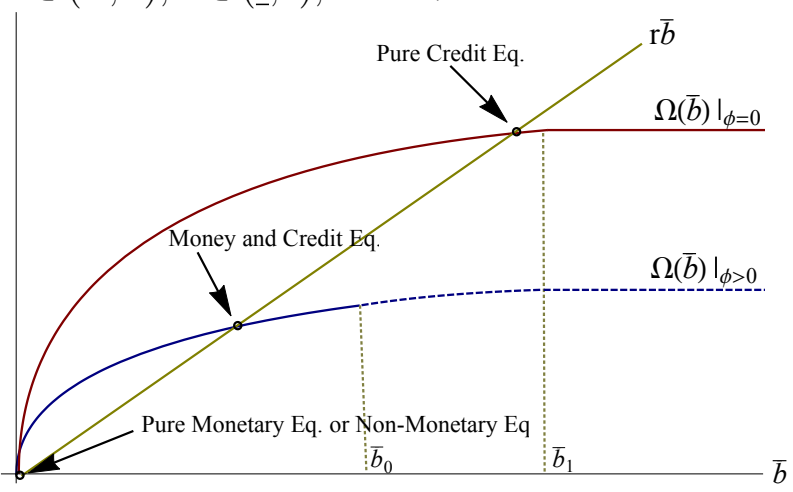

\subsubsection{Perfect Record-Keeping}

We now turn to a special case of the model with perfect record-keeping $(\Lambda=1)$. As before, the flow cost of default depends on whether or not money is valued. When money is not valued, the right side of (17) is given by

$$
\left.\Omega(\bar{b})\right|_{\phi=0}=\sigma \theta S(\bar{b}),
$$

which is strictly concave if $\bar{b} \in\left[0, \bar{b}_{1}\right)$ and linear otherwise. As before, since a non-monetary equilibrium always exists, $\left.\Omega(\bar{b})\right|_{\phi=0}$ is defined for all $\bar{b} \in[0, \infty)$.

When money is valued, (13) and (14) at equality implies a buyer chooses his real balances so that his total wealth is the same as a buyer who defaults: $z+\bar{b}=\widetilde{z}$. In that case, the right side of (17) when money is valued and $\Lambda=1$ is given by

$$
\left.\Omega(\bar{b})\right|_{\phi>0}=i \bar{b}
$$

which is linear with a slope of $i$ for all $\bar{b} \in\left[0, \bar{b}_{0}\right)$. This is depicted by the straight blue line in Figures 8 and 9 .

When $\Lambda=1$, a necessary condition for credit is that the slope of $\left.\Omega(\bar{b})\right|_{\phi=0}$ at $\bar{b}=0$ is greater than the slope of $r \bar{b}$. Given money is not valued, credit is feasible if $\sigma \theta S^{\prime}(0)>r$, or

$$
r<\frac{\sigma \theta}{1-\theta} \equiv \bar{i}
$$

which is the same necessary condition for a pure credit equilibrium derived in Section 4.2, but with $\Lambda=1$ in (19). Moreover, there is a positive debt limit where money is not valued if $r<i<\bar{i}$ or $i<r<\bar{i}$, which implies there is at most one positive intersection of $\left.\Omega(\bar{b})\right|_{\phi=0}$ with $r \bar{b}$. If $i=r<\bar{i}$, 
the debt limit is indeterminate and there are a continuum of debt limits where $\bar{b} \in\left[0, \bar{b}_{0}\right]$. Finally if $r \geq \bar{i}$, credit is not feasible and the only solution to (17) is $\bar{b}=0$.

Figure 8: Pure Monetary and Pure Credit Equilibrium when $\Lambda=1$ and $r<i<\bar{i}$

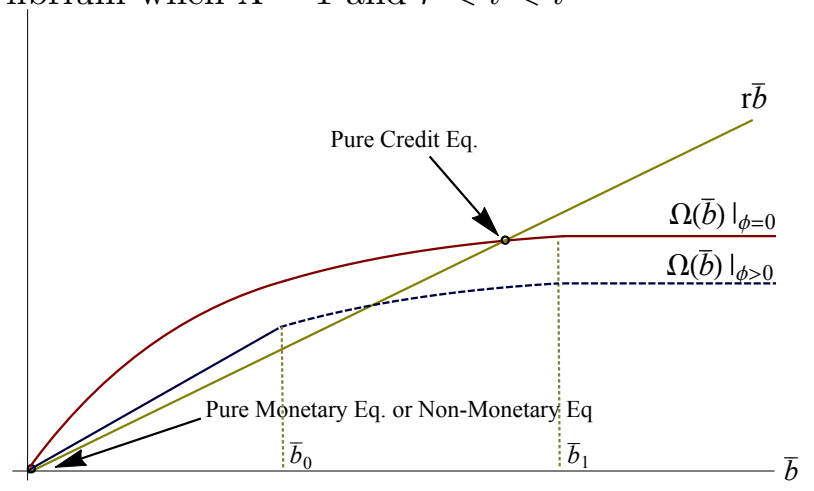

Figure 9: Pure Monetary and Pure Credit Equilibrium when $\Lambda=1$ and $i<r<\bar{i}$

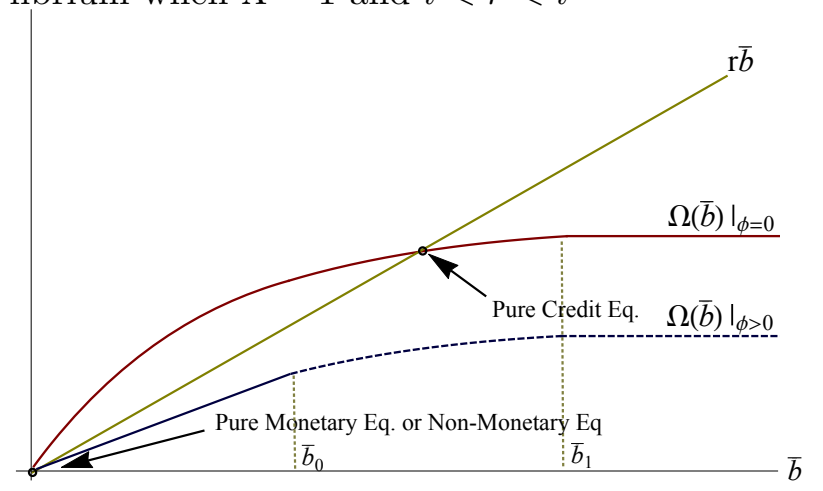

Can money and credit coexist under perfect record-keeping? We prove in the special case of our model with $\Lambda=1$, the answer is generally no. While a formal proof is in the Appendix, the reasoning is illustrated in Figure 10, which plots the right side of (23) against $i$ when $\Lambda=1$. In Figure 10, the determination of $\widetilde{i}$ occurs at $\underline{i}=r$, which is the intersection of the 45-degree line and the right side of (23). Consequently, $\widetilde{i}=\underline{i}=r$ when $\Lambda=1$, which means the existence region for a money and credit equilibrium, $i \in(\underline{i}, \widetilde{i})$, collapses to a single point, $\widetilde{i}=\underline{i}=r$. Consequently, a money and credit equilibrium ceases to exist when $\Lambda=1$ and $i \neq r$.

Notice in the knife edge case where $\Lambda=1$ and $i=r<\bar{i}$, the money supply is constant and there are a continuum of debt limits, $\bar{b} \in\left[0, \bar{b}_{0}\right]$, that satisfy (17). In each of these equilibria, allocations are identical in payoffs. In turn, any exogenous change in policy that affects the debt limit is perfectly offset by a change in real balances so that the buyer's total wealth is the same. In that case, money and credit are not both needed.

We summarize our main coexistence results for the model with $\Lambda \in(0,1]$ in the following proposition.

Proposition 1. Given $\Lambda \in(0,1]$ and $i>0$, the following outcomes are possible.

1. When $\Lambda \in(\bar{\Lambda}, 1)$, a money and credit equilibrium exists if and only if $i \in(\underline{i}, \widetilde{i})$, and coexists with a pure monetary equilibrium, a pure credit equilibrium, and a non-monetary equilibrium without credit.

2. When $\Lambda=1$, a money and credit equilibrium does not exist for any $i \neq r$. 
Figure 10: Determination of $\widetilde{i}$ when $\Lambda=1$

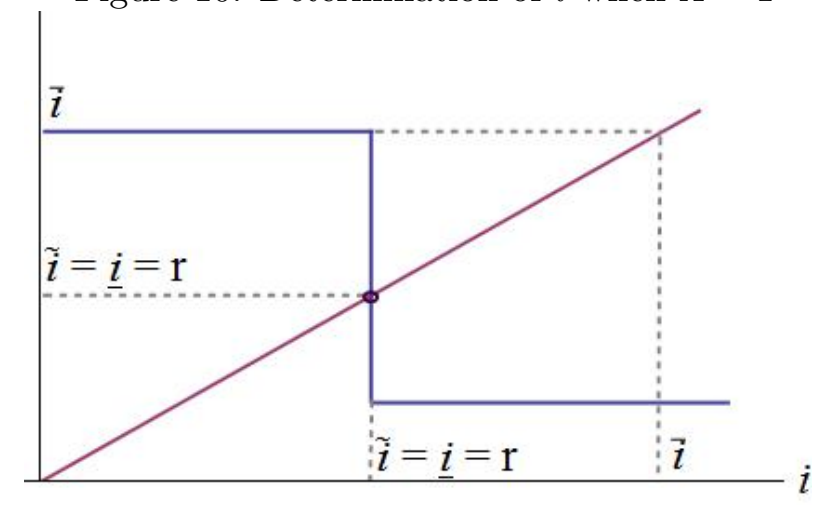

(a) If $r<i<\bar{i}$ or $i<r<\bar{i}$, there exists a pure monetary equilibrium, a pure credit equilibrium, and a non-monetary equilibrium without credit.

(b) If $i<\bar{i}$ and $r \geq \bar{i}$, there exists a pure monetary equilibrium and a non-monetary equilibrium without credit, but not a pure credit equilibrium.

(c) If $i \geq \bar{i}$ and $r<\bar{i}$, there exists a pure credit equilibrium and a non-monetary equilibrium without credit, but not a pure monetary equilibrium.

(d) If $i=r<\bar{i}$, there exists a pure monetary equilibrium, a pure credit equilibrium, a nonmonetary equilibrium without credit, and a continuum of equilibria where the debt limit is indeterminate.

Proposition 1 highlights an important dichotomy between monetary and credit trades when record-keeping is perfect: there can be trades with credit only or trades with money only, but generally not trades with both money and credit. This special case also points to the fundamental difficulty of getting money and credit to coexist when all trades are identical and record-keeping is perfect: either only credit is used as money becomes inessential, or only money is used since the incentive to renege on debt repayment is too high. This also captures the insight by Kocherlakota (1998) that there is no social role for money in an economy with perfect record-keeping.

\subsubsection{Comparative Statics}

Having characterized existence of a money and credit equilibrium, we now discuss some comparative statics for effects on the debt limit summarized in the table below. In what follows, we focus on equilibria where money is valued and credit is feasible. 


\begin{tabular}{|c|c|c|c|c|}
\hline$\frac{\partial \bar{b}}{\partial \Lambda}$ & $\frac{\partial \bar{b}}{\partial \sigma}$ & $\frac{\partial \bar{b}}{\partial i}$ & $\frac{\partial \bar{b}}{\partial r}$ & $\frac{\partial \bar{b}}{\partial \theta}$ \\
\hline+ & + & + & - & + \\
\hline
\end{tabular}

An increase in the fraction of the sellers with access to record-keeping, $\Lambda$, increases the right side of (17), which shifts up both $\left.\Omega(\bar{b})\right|_{\phi=0}$ and $\left.\Omega(\bar{b})\right|_{\phi>0}$ and induces an increase in $\bar{b}$. When more sellers accept credit, the gain for buyers from using and redeeming credit increases, which relaxes the debt limit. The increase in $\Lambda$ can be high enough so that credit drives money out of circulation. When $\Lambda=1$ and $i \neq r$, a money and credit equilibrium disappears, in which case there can only be a pure monetary equilibrium, a pure credit equilibrium, and a non-monetary equilibrium without credit.

An increase in inflation generates a similar qualitative effect. In this way, inflation has two effects in this model: first, is the usual effect on reducing the purchasing power of money, which reduces trade and hence welfare; second, is the effect on reducing agents' incentive to default. Intuitively, an increase in the inflation tax relaxes the credit constraint by increasing the cost of default, since defaulters need to bring enough money to finance their consumption.

In sum, the debt limit depends on the fraction of credit trades, the extent of trading frictions, the rate of return on money, agents' patience, and the buyer's bargaining power. The larger the fraction of sellers that accept credit, the lower the rate of return on money, or the more patient agents become, the less likely the credit constraint will be binding. In these cases, the buyer can credibly promise to repay more, which induces cooperation in credit arrangements thereby relaxing the debt limit.

\subsection{Multiple Equilibria}

A key feature of the model is the presence of multiple steady-state equilibria where different transactions patterns coexist. The next proposition summarizes possible cases for multiplicity, which builds on the analysis from the previous subsections.

Proposition 2. Given $\Lambda \in(0,1]$ and $i>0$, the following cases are possible.

1. When $i<\bar{i}$, equilibrium can be either (i) a pure monetary equilibrium and autarky if $\Lambda \leq \bar{\Lambda}$; (ii) a pure monetary equilibrium, a pure credit equilibrium, and autarky if $\Lambda>\bar{\Lambda}$; or (iii) a pure monetary equilibrium, a pure credit equilibrium, a money and credit equilibrium, and autarky if and only if $\Lambda \in(\bar{\Lambda}, 1)$ and $i \in(\underline{i}, \widetilde{i})$ or if $\Lambda=1$ and $i=r$.

2. When $i \geq \bar{i}$, equilibrium can be either (i) autarky if $\Lambda \leq \bar{\Lambda}$; or (ii) a pure credit equilibrium and autarky if $\Lambda>\bar{\Lambda}$. 


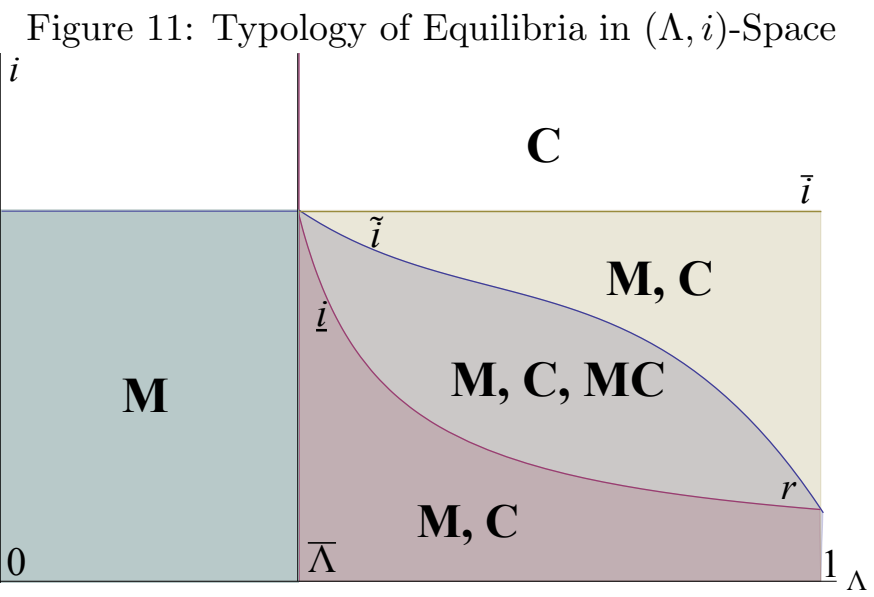

Notice that a non-monetary equilibrium and an equilibrium without credit always exists for any combinations of parameters. In Figure 11, we illustrate the typology of active steady-state equilibria in $(\Lambda, i)$-space. The active steady-states correspond to a pure credit equilibrium $(C)$, a pure monetary equilibrium $(M)$, and a mixed equilibrium where both money and credit are used $(M C)$. As shown in Section 4.3, the existence of the $M C$ region requires both heterogenous record-keeping across sellers and imperfect enforcement. With perfect record-keeping $(\Lambda=1)$, a money and credit equilibrium generally does not exist, as shown in Proposition 1. And with perfect enforcement, our model reduces to the model in Nosal and Rocheteau (2011), where there is no equilibrium where a buyer uses both money and credit in a DM transaction.

\section{$5 \quad$ Endogenous Record-Keeping}

We now consider the choice of accepting credit by making $\Lambda$ endogenous. In order to accept credit, sellers must invest ex-ante in a costly record-keeping technology that records and authenticates an IOU proposed by the buyer. ${ }^{16}$ The per-period cost of this investment in terms of utility is $\kappa \geq 0$, drawn from a cumulative distribution $F(\kappa): \mathbb{R}_{+} \rightarrow[0,1]$. Sellers are heterogenous according to their record-keeping cost and are indexed by $\kappa$. For instance, $\kappa$ captures an explicit adoption cost component and an implicit opportunity or cognitive cost component that varies across sellers in

\footnotetext{
${ }^{16}$ This cost can also reflect issues of fraud and information problems that permeate the credit industry such as credit card fraud, identity theft, and the need to secure confidential information. Besides being a costly drain on banks and retailers that accept credit, these problems may erode consumer confidence in the credit card industry. See Roberds and Schreft (2009) for a discussion and Li, Rocheteau, and Weill (2012) for a recent model of fraud.
} 
different industries or sectors. ${ }^{17}$

At the beginning of each period, sellers decide whether or not to invest in the record-keeping technology. When making this decision, sellers take as given buyers' choice of real balances and the debt limit. The seller's problem is given by

$$
\max \{-\kappa+\sigma(1-\theta) S(z+\bar{b}), \sigma(1-\theta) S(z)\}
$$

According to (24), a seller who invests incurs the disutility cost $\kappa>0$ that allows him to extend a loan to the buyer. In that case, the seller extracts a constant fraction $(1-\theta)$ of the total surplus, $S(z+\bar{b})$. If the seller does not invest, then he can only accept money, and gets $(1-\theta)$ of $S(z)$. Since total surplus is increasing in the buyer's wealth, the total surplus from accepting credit is at least as large as the total surplus from not accepting credit, $S(z+\bar{b})>S(z)$.

In addition, there exists a threshold for the record-keeping cost, $\bar{\kappa}$, below which sellers invest and above which they do not invest. From (24), this threshold is given by

$$
\bar{\kappa} \equiv \sigma(1-\theta)[S(z+\bar{b})-S(z)]
$$

and gives an individual seller's expected benefit of accepting credit. Given $\kappa$, let $\lambda(\kappa) \in[0,1]$ denote an individual seller's decision to invest. This decision problem is given by

$$
\lambda(\kappa)=\left\{\begin{array} { c } 
{ 1 } \\
{ [ 0 , 1 ] } \\
{ 0 }
\end{array} \text { if } \kappa \left\{\begin{array}{l}
< \\
=\bar{\kappa} . \\
>
\end{array}\right.\right.
$$

According to (26), all sellers with $\kappa<\bar{\kappa}$ invest since the benefit exceeds the cost; sellers with $\kappa>\bar{\kappa}$ do not invest; and any seller with $\kappa=\bar{\kappa}$ invests with an arbitrary probability since they are indifferent. Consequently, the aggregate measure of sellers that invest is given by the measure of sellers with $\kappa \leq \bar{\kappa}$ :

$$
\Lambda \equiv \int_{0}^{\infty} \lambda(\kappa) d F(\kappa)=F(\bar{\kappa})
$$

Definition 2. A stationary equilibrium with endogenous record-keeping is a list $\left(q, q^{c}, z, \widetilde{z}, \bar{b}, \lambda(\kappa), \Lambda\right)$

\footnotetext{
${ }^{17}$ In addition to being a plausible assumption in reality (see e.g. Garcia-Swartz, Hahn, and Layne-Farrar (2006)), another reason we assume $\kappa$ potentially differs across sellers is because when all sellers have the same $\kappa$, an interior equilibrium where a positive measure of sellers invest is not stable in the following sense. Suppose $\Lambda \in(0,1)$ is an equilibrium when all sellers have the same $\kappa$. If we perturb the equilibrium slightly to $\Lambda+\epsilon$ for an arbitrarily small $\epsilon>0(\epsilon<0)$, then it is a best response for all sellers (no sellers) to invest. In addition, while we assume here that $\kappa$ is a fixed flow cost, having a one-time cost may be more suitable in some applications but does not affect the key insights of our analysis. See also Lester, Postlewaite, and Wright (2012) and Zhang (2014) for a related discussion and further applications.
} 
that solves (9), (10), (13), (14), (17), (26), and (27).

Equilibrium with endogenous record-keeping can be determined recursively. We first determine the debt limit for a given measure of sellers that invest and value of money, as in Section 4. Next, we determine sellers' investment decisions given the debt limit and value of money. We assume that all sellers have the same expectations about the value of money and that these expectations are rational and consistent with buyers' portfolio choices. Having jointly determined $(\bar{b}, \Lambda)$, all other endogenous variables follow directly from the analysis in the previous sections.

\subsection{Equilibrium Debt Limit}

In the following lemma, we summarize how the debt limit depends on the measure of sellers with access to record-keeping, $\Lambda$, and value of money, $\phi$. Our characterization below focuses on positive solutions to the debt limit (we know that $\bar{b}=0$ is always a solution to (17) for any $\Lambda$, whether or not money is valued). To simplify the presentation, we assume in what follows that $i \geq \hat{i}$ so that the threshold $\bar{b}_{0}$ exists; the analysis when $i<\widehat{i}$ is similar except we would replace $\bar{b}_{0}$ with $\bar{b}_{1}-\bar{z}$.

Lemma 4. Define $\Lambda_{0}$ as the value of $\Lambda$ when $\bar{b}=\bar{b}_{0}$ solves (17), and $\Lambda_{1}$ as the value of $\Lambda$ when $\bar{b}=\bar{b}_{1}$ solves (17).

1. When money is not valued, the debt limit, $\left.\bar{b}(\Lambda)\right|_{\phi=0}$, is strictly increasing and convex in $\Lambda$ for all $\Lambda \in\left(\bar{\Lambda}, \Lambda_{1}\right)$ and is increasing and linear for all $\Lambda \in\left[\Lambda_{1}, 1\right)$.

2. When money is valued, the debt limit, $\left.\bar{b}(\Lambda)\right|_{\phi>0}$, is strictly increasing and convex in $\Lambda$ for all $\Lambda \in\left(\frac{r}{i}, \Lambda_{0}\right)$.

In Lemma $4,\left.\bar{b}(\Lambda)\right|_{\phi=0}$ is defined if and only if credit is feasible, or $\Lambda>\bar{\Lambda}$. Similarly, $\left.\bar{b}(\Lambda)\right|_{\phi>0}$ is defined for $\Lambda \in\left(\frac{r}{i}, \Lambda_{0}\right)$ since the existence condition for a money and credit equilibrium, $i \in(\underline{i}, \widetilde{i})$, is satisfied if and only if $\Lambda \in\left(\frac{r}{i}, \Lambda_{0}\right)$.

\subsection{Equilibrium Measure of Sellers That Invest in Record-Keeping}

Given a debt limit and choice of real balances by buyers, sellers decide whether to invest in the record-keeping technology. For an individual seller, this decision is determined by (26) and hence depends on the expected benefit of investing, $\bar{\kappa}$.

Depending on the distribution of the cost function, $F(\kappa)$, there can be any number of solutions to $\Lambda$, though in our analysis below we give simple conditions to ensure an interior equilibrium where a positive measure of sellers invest. Indeed a special case is when the record-keeping cost is zero for 
Figure 12: $(\bar{b}, \Lambda)$ when $i \in(r, \bar{i})$ and $F(\kappa)$ is Degenerate

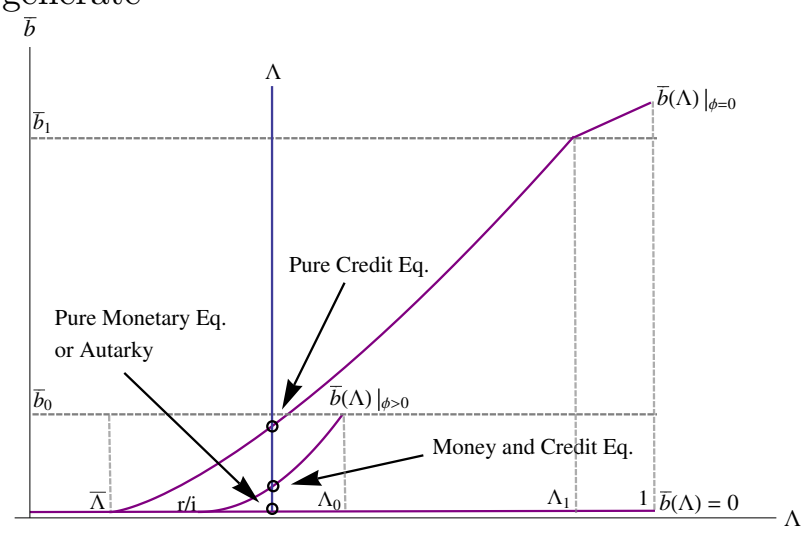

Figure 13: $(\bar{b}, \Lambda)$ when $i \geq \bar{i}$ and $F(\kappa)$ is Degenerate

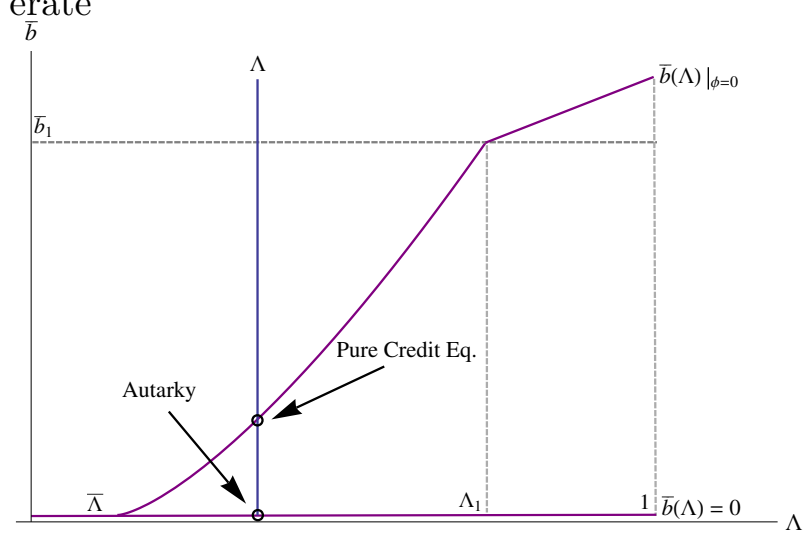

a constant fraction $\Lambda$ of sellers and infinite for the rest, as in Section 4, which implies the measure of sellers investing is constant at $\Lambda$ for any debt limit. While it is clearly desirable to proceed with more general cost functions where $F(\kappa)$ is non-degenerate so the measure of sellers investing can depend on the debt limit, we present this simple example first to illustrate our basic methodology. In that case, the fraction of sellers accepting credit, $\Lambda$, is represented by the vertical line in Figures 12 and 13 when $i \in(r, \bar{i})$ and $i \geq \bar{i}$, respectively. ${ }^{18}$ Since there is always at least one intersection of $\Lambda$ with either $\left.\bar{b}(\Lambda)\right|_{\phi=0},\left.\bar{b}(\Lambda)\right|_{\phi>0}$, or $\bar{b}(\Lambda)=0$, an equilibrium with endogenous debt limits and record-keeping exists, and for any $\Lambda>\bar{\Lambda}$, we know from Section 4 that there exists at least one positive solution to the debt limit.

We now turn to the more general case where $F(\kappa)$ is possibly non-degenerate. To ensure an interior solution, we assume $\kappa$ is zero for a positive measure of sellers and that $\kappa$ is arbitrarily high for a positive measure of sellers. As with our characterization of the debt limit, here we distinguish two cases for the seller's benefit of investing: (1) when money is not valued $(\phi=0)$ and (2) when money is valued $(\phi>0)$. These are given respectively by

$$
\begin{gathered}
\left.\bar{\kappa}(\bar{b})\right|_{\phi=0} \equiv \sigma(1-\theta) S(\bar{b}), \\
\left.\bar{\kappa}(\bar{b})\right|_{\phi>0} \equiv \sigma(1-\theta)[S(z+\bar{b})-S(z)],
\end{gathered}
$$

which are both increasing in the loan size, $\bar{b}$. Given $\left.\bar{\kappa}(\bar{b})\right|_{\phi=0}$ and $\left.\bar{\kappa}(\bar{b})\right|_{\phi>0}$, we denote the corresponding measure of sellers that invest by $\left.\Lambda(\bar{b})\right|_{\phi=0}$ and $\left.\Lambda(\bar{b})\right|_{\phi>0}$, respectively. The following

\footnotetext{
${ }^{18}$ The condition $i \in(r, \bar{i})$ ensures an equilibrium with money and credit is possible. An equilibrium with money and credit is not possible if $i \in(0, r)$, while monetary equilibrium is not possible if $i \geq \bar{i}$.
} 
lemma summarizes how sellers' aggregate investment decisions depends on the debt limit and value of money.

Lemma 5. Define $\Lambda_{s}$ as the measure of sellers that invest when $\bar{b}=\bar{b}_{1}$.

1. When money is not valued, the measure of sellers that invest, $\left.\Lambda(\bar{b})\right|_{\phi=0}$, is strictly increasing in $\bar{b}$ for all $\bar{b} \in\left[0, \bar{b}_{1}\right)$ and constant at $\Lambda_{s} \leq 1$ for all $\bar{b} \geq \bar{b}_{1}$.

2. When money is valued, the measure of sellers that invest, $\left.\Lambda(\bar{b})\right|_{\phi>0}$, is strictly increasing in $\bar{b}$ for all $\bar{b} \in\left[0, \bar{b}_{0}\right)$.

Figure 14: $(\bar{b}, \Lambda)$ when $i \in(r, \bar{i})$ and $F(\kappa)$ is Non-Degenerate

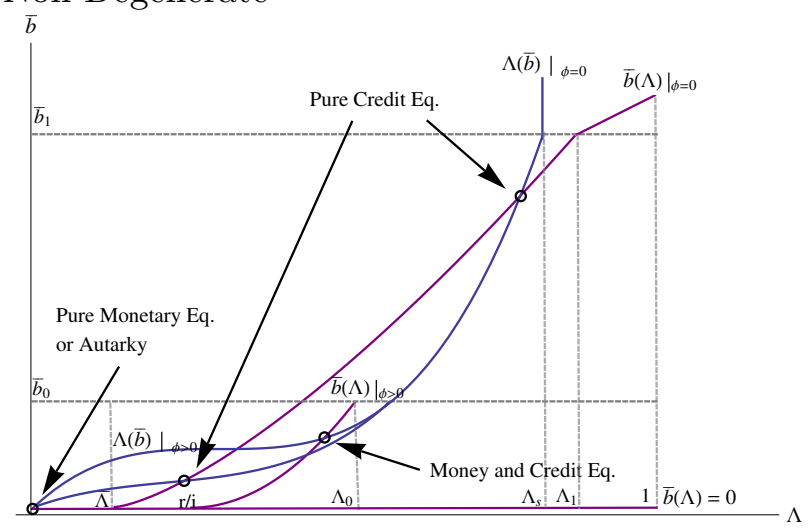

Figure 15: $(\bar{b}, \Lambda)$ when $i \geq \bar{i}$ and $F(\kappa)$ is NonDegenerate

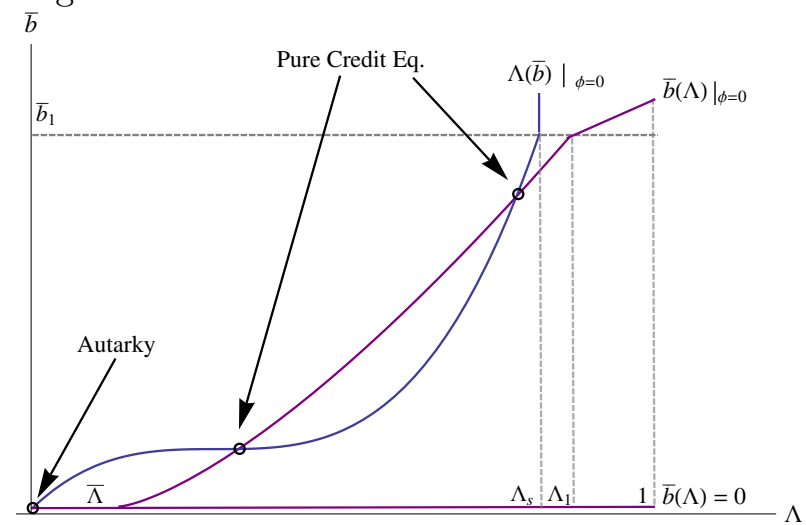

Together, Lemma 4 and Lemma 5 help determine an equilibrium with endogenous recordkeeping summarized in the following proposition.

Proposition 3. Suppose that $F(\kappa): \mathbb{R}_{+} \rightarrow[0,1]$ is such that $\kappa$ is zero for a positive measure of sellers and $\kappa$ is arbitrarily high for a positive measure of sellers. Equilibrium with endogenous record-keeping exists, and given $i>0$, multiple steady-state equilibria are possible.

An example of Proposition 3 where $F(\kappa)$ is non-degenerate is illustrated in Figures 14 and 15 when $i \in(r, \bar{i})$ and $i \geq \bar{i}$, respectively. ${ }^{19}$ In Figure 14, the correspondences for $\bar{b}$ and $\Lambda$ intersect multiple times, corresponding to multiple steady-state equilibria with endogenous debt limits and record-keeping. There is (i) a pure monetary equilibrium where no sellers accept credit, (ii) a money and credit equilibrium where a fraction of sellers accept both money and credit, (iii) two

\footnotetext{
${ }^{19}$ The examples in Figures 14 and 15 assume $u(q)=2 \sqrt{q}, c(q)=q, F(\kappa)=\left(\frac{1}{1+\exp ^{-(\kappa-\mu)}}\right), \sigma=0.5, \theta=0.8$, $r=0.02, \mu=2$, and $i=0.3$.
} 
pure credit equilibria where money is not valued and a fraction of sellers accept credit, and (iv) a non-monetary equilibrium without credit, or autarky. In Figure 15, the only possible outcomes are credit alone or autarky since $i \geq \bar{i}$ implies a monetary equilibrium cannot exist.

More generally, while there can be any number solutions to $\Lambda$ for an arbitrary $F(\kappa)$, we know that for any $\Lambda$, we can determine the debt limit according to Lemma 4 . Then once $(\bar{b}, \Lambda)$ are jointly determined, we can easily obtain all other endogenous variables, namely $\left(q, q^{c}, z, \widetilde{z}\right)$ from Definition 2. Given $i>0$, so that we are not at the Friedman rule, it is also possible to have multiple steady-state equilibria with different values for $(\Lambda, \bar{b})$ and in turn, different configurations in the usage of money and credit.

The multiplicity of equilibria arises through the general equilibrium effects in the trading environment that produce strategic complementarities between buyers' and sellers' decisions. ${ }^{20}$ As is evident from the upward sloping curves in Figure 14, the measure of sellers who invest is increasing in the debt limit and vice versa. When more sellers invest in the costly record-keeping technology, the gain for buyers from using credit also increase. As default becomes more costly, the incentive to renege falls which raises the debt limit. At the same time, when more sellers accept credit, then money is needed in a smaller fraction of matches. So long as holding money is not too costly, buyers carry fewer real balances. This gives sellers an even greater incentive to accept credit, which raises the debt limit and further reduces the buyer's real balances. ${ }^{21}$

\section{Welfare}

We now turn to examining the model's normative properties by comparing the types of steady-state equilibria in terms of social welfare. Here we assume social welfare is measured by the steady-state sum of buyers' and sellers' utilities:

$$
\mathcal{W} \equiv \sigma[\Lambda S(z+\bar{b})+(1-\Lambda) S(z)]-k
$$

where $k \equiv \int_{0}^{\bar{\kappa}} \kappa d F(\kappa)$ is the aggregate record-keeping cost averaged across individual sellers. Table 1 summarizes social welfare in the three types of active equilibria discussed in the previous sections.

\footnotetext{
${ }^{20}$ Strategic complementarities between the seller's decision to invest and the buyer's choice of real balances is also present under perfect enforcement as in Nosal and Rocheteau (2011). The complementarities in our model captures both an extensive margin effect (on the number of credit trades) and intensive margin effect (on the amount borrowed per trade), whereas the latter intensive margin channel is absent in Nosal and Rocheteau (2011).

${ }^{21}$ The complementarities in this paper are also similar to the complementarities between sellers' investment decisions and buyers' portfolios in Lester, Postlewaite, and Wright (2012). In our model, there are also complementarities between the actions of current and future agents which is present even in the model with exogenous record-keeping: if more future sellers accept credit, default by buyers becomes more costly, relaxing the debt limit today.
} 
Table 1: Social Welfare Across Steady-State Equilibria

\begin{tabular}{cc}
\hline \hline Equilibrium & SteAdY-State Welfare \\
\hline Pure Monetary Eq. & $\mathcal{W}^{m}=\sigma S(z)$ \\
Pure Credit Eq. & $\mathcal{W}^{c}=\sigma \Lambda S(\bar{b})-k$ \\
Money and Credit Eq. & $\mathcal{W}^{m c}=\sigma[\Lambda S(z+\bar{b})+(1-\Lambda) S(z)]-k$ \\
\hline
\end{tabular}

Figure 16 plots an example of welfare in the three types of equilibria as a function of the cost of holding money, $i{ }^{22}$ At $i=0$, which is the Friedman rule, Kalai bargaining implies an efficient economy can run without credit. In that case, welfare in a pure monetary equilibrium is at its maximum, $\mathcal{W}^{\max } \equiv \sigma\left[u\left(q^{*}\right)-c\left(q^{*}\right)\right]$, and strictly dominates welfare in a pure credit equilibrium since sellers must incur the real cost of technological adoption. Hence when record-keeping is costly, a pure credit equilibrium is socially inefficient even when $r \leq r^{*}$ so that credit alone can achieve the first-best. As $i$ increases, it may be possible that $\mathcal{W}^{m}<\mathcal{W}^{c}$ which occurs if $i>i_{c}$, where $i_{c}$ is the value of $i$ such that $\mathcal{W}^{m}=\mathcal{W}^{c}$ :

$$
S\left[z\left(i_{c}\right)\right]=\Lambda S(\bar{b})-k .
$$

We can also have $\mathcal{W}^{m}<\mathcal{W}^{c}$ if the aggregate record-keeping cost is low enough - that is, if $k<\sigma[\Lambda S(\bar{b})-S[z(i)]]$, or if inflation is high enough, as illustrated in Figure 16. However, the welfare-dominated monetary equilibrium may still prevail due to a rent-sharing externality: since sellers incur the full cost of technological adoption but only obtain a fraction $(1-\theta)$ of the total surplus, they fail to internalize the full benefit of accepting credit. Consequently, there can be coordination failures and excess inertia in the decision to accept credit, in which case the economy can still end up in the Pareto-inferior monetary equilibrium.

We also compare welfare in a money and credit economy with welfare in a pure monetary economy and pure credit economy. Recall the necessary condition for a money and credit equilibrium is $i \in(\underline{i}, \widetilde{i})$. When $i=\underline{i}$, credit is no longer feasible if money is valued, in which case $\mathcal{W}^{m c}=\sigma S(z)=\mathcal{W}^{m}$. Alternatively when $i=\widetilde{i}$, money is no longer valued if there is credit, in which case $\mathcal{W}^{m c}=\sigma \Lambda S(\bar{b})-k=\mathcal{W}^{c}$. In the example in Figure 16, we therefore have $\mathcal{W}^{m c}>\mathcal{W}^{m}$ and $\mathcal{W}^{m c}>\mathcal{W}^{c}$ for $i \in(\underline{i}, \widetilde{i})$ given the threshold $i_{c}$ exists. To be clear however, the welfare rankings in Figure 16 are not generic and will depend on fundamentals like the record-keeping cost. For instance, if $\kappa$ is very high, then for $i \in(\underline{i}, \widetilde{i})$, the surplus from accepting credit can be low enough

\footnotetext{
${ }^{22}$ The example in Figure 16 assumes $u(q)=2 \sqrt{q}, c(q)=q, F(\kappa)=\left(\frac{1}{1+\exp ^{-(\kappa-\mu)}}\right), \sigma=0.5, \theta=0.8, r=0.02$, $\mu=2$, and varies $i$.
} 
Figure 16: Welfare in a Pure Monetary, Money and Credit, and Pure Credit Equilibrium

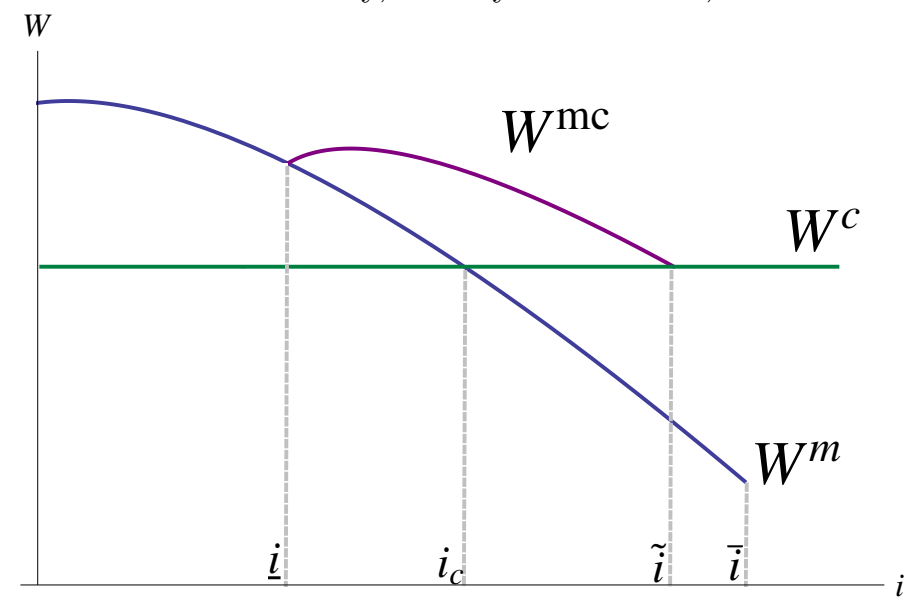

that $\mathcal{W}^{m}>\mathcal{W}^{m c}>\mathcal{W}^{c}$

\section{Effects of Inflation on Welfare}

We now consider the welfare effects of a perfectly anticipated change in inflation for the three types of payment regimes. The presence of multiple equilibria for the same fundamentals makes the choice of optimal policy difficult to analyze in full generality since we must deal with the issue of equilibrium selection. In regions with multiplicity, we assume agents coordinate on a particular equilibrium and then analyze the effects of inflation in that equilibrium. We also begin by taking $\Lambda \in(0,1)$ as given.

Figure 17: Welfare in a Money and Credit Equilibrium when $\Lambda>\widehat{\Lambda}$

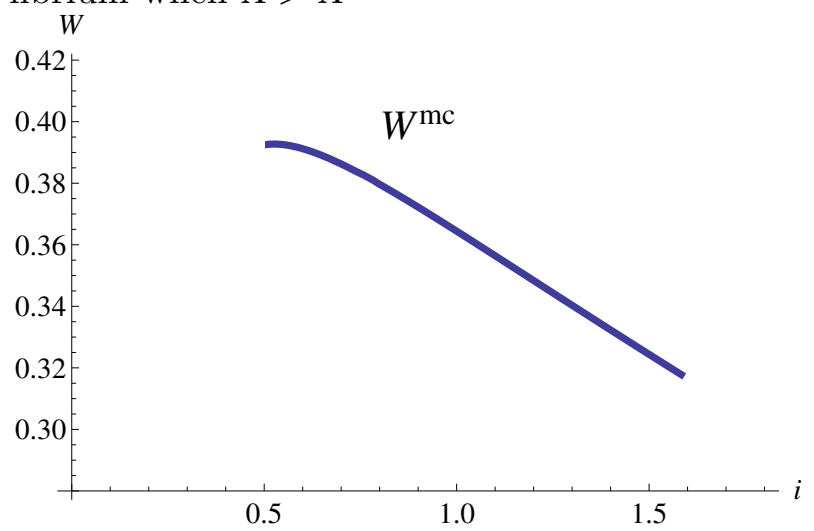

Figure 18: Welfare in a Money and Credit Equilibrium when $\Lambda<\widehat{\Lambda}$

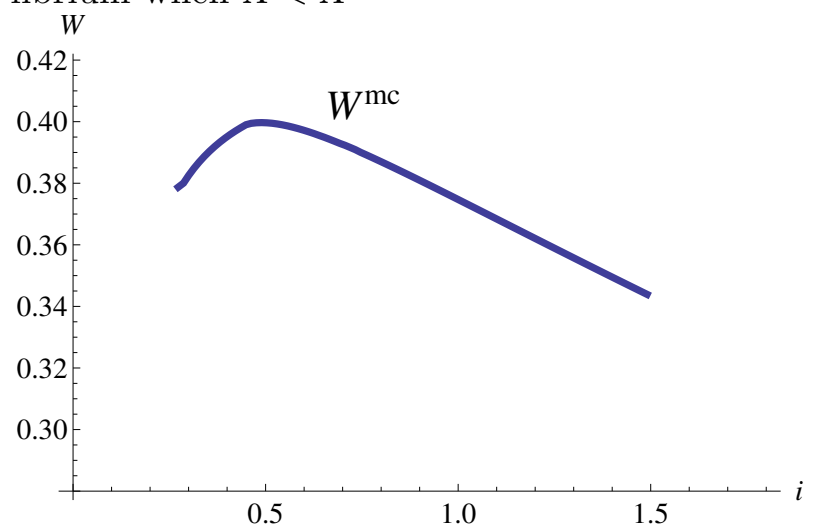


In a pure credit equilibrium inflation has no effect on welfare for any $i>0$. This is illustrated by the horizontal green line in Figure 16. In a pure monetary equilibrium, which is possible if $i<\bar{i}$, welfare is decreasing in the inflation rate: $\frac{d \mathcal{W}_{m}}{d i}=\sigma S^{\prime}(z) \frac{d z}{d i}<0$ since $\frac{d z}{d i}<0$ for any $i<\bar{i}$. If lumpsum taxes can be enforced, then optimal policy corresponds to the Friedman rule. Indeed when $i=0$, holding money is costless so there is no need for credit. In that case, deflation completely crowds out credit as money alone is enough to finance the first best. ${ }^{23}$

In a money and credit equilibrium, the effect of inflation on welfare is given by

$$
\frac{d \mathcal{W}_{m c}}{d i}=\sigma \Lambda S^{\prime}(z+\bar{b})\left[\frac{d z}{d i}+\left(\frac{d z}{d \bar{b}}+1\right) \frac{d \bar{b}}{d i}\right]+\sigma(1-\Lambda) S^{\prime}(z) \frac{d z}{d i}
$$

where $\frac{d z}{d i}<0, \frac{d z}{d \bar{b}} \in(-1,0)$, and $\frac{d \bar{b}}{d i}>0$. In general, the sign of (29) is ambiguous and depends on the relative magnitudes of two counteracting effects: the effect of inflation on real balances $\left(\frac{d z}{d i}<0\right)$ and the effect of inflation on the debt limit $\left(\frac{d \bar{b}}{d i}>0\right)$. In Appendix A, we derive a sufficient condition for inflation to have a negative effect on welfare. Specifically, when $\Lambda \approx 0$ or $\Lambda>\widehat{\Lambda} \equiv \frac{S^{\prime \prime}(z)}{S^{\prime \prime}(z)+S^{\prime \prime}(z+\bar{b})}, \frac{d \mathcal{W}^{m c}}{d i}<0$. Figure 17 plots an example illustrating inflation's negative effect on $\mathcal{W}^{m c}$. However, when $\Lambda \in(0, \widehat{\Lambda})$, inflation can have a positive effect on welfare, as in Figure 18. While inflation unambiguously decreases welfare in the $(1-\Lambda)$ trades involving money only, inflation relaxes borrowing constraints in the $\Lambda$ trades with both money and credit. So long as $\Lambda$ is not too large, the latter effect may dominate so that an increase in inflation can raise aggregate welfare. Intuitively, when $\Lambda$ is high, the marginal surplus of using credit is low since the debt limit is high whereas the marginal surplus of using money is very high in the $(1-\Lambda)$ cash-only transactions. Hence when $\Lambda>\widehat{\Lambda}$, an increase in inflation does not increase the surplus as much in money-credit trades as it reduces the surplus in cash-only trades.

Figure 16 and 18 show examples where an increase in inflation raises welfare in a money and credit economy. Globally however, maximum welfare in a money and credit economy is strictly dominated by welfare in a pure monetary economy at the Friedman rule, as in Figure 16. In that case, money works too well and there is no social role for credit. The Friedman rule remains the globally optimal monetary policy, which implements the first-best allocation and saves society on record-keeping costs.

When $\Lambda$ is endogenous, the positive effect of inflation on welfare is amplified and generates additional feedback effects. Since an increase in inflation raises the debt limit, sellers have a greater incentive to accept credit, which further relaxes the debt limit and the amount borrowed by the buyer. When the debt limit relaxes to the point where buyers are no longer liquidity constrained,

\footnotetext{
${ }^{23}$ As we show in Appendix B, the Friedman rule may not be feasible since it requires taxation and individuals may choose to renege on their tax obligation if it is too high. In that case, the first best can only be achieved with credit.
} 
money is no longer valued. In that case, agents can still trade the first-best level of output even when monetary authorities do not implement the Friedman rule. However, such an equilibrium is not socially efficient since sellers must still incur the real cost of technological adoption.

\section{Conclusions}

As many economies increasingly rely on credit cards both as a payment instrument and a means for borrowing, it is increasingly important to understand how individuals substitute between cash and credit. Despite the increasing availability of unsecured lending such as credit cards loans, consumers still demand paper currency and liquid assets for a sizeable share of transactions. That money and credit coexist appears to be the norm across many economies, and one goal of this paper is to delve deeper into understanding why.

To that end, we build a simple model of money and credit that integrates two deep frictions motivating payment decisions: imperfect record-keeping and limited commitment. In order to capture the two-sided nature of actual payment systems, we jointly model the acceptability of credit by merchants and the debt repayment decision by consumers. So long as record-keeping is imperfect, money and credit coexist for a range of nominal interest rates. However, in a special case of our model with perfect record-keeping, the classic Kocherlakota (1998) wisdom appears: when credit is feasible, there is no social role for money, and when money is valued, credit cannot be sustained.

Our theory also highlights a strategic complementarity between buyers' credit limit and sellers' decision to accept credit. Multiple steady-state equilibria and coordination failures can therefore arise due to the two-sided nature of the retail payment system. This potential for coordination failures also raises new concerns for policymakers as economies with similar technologies, institutions, and policies can still end up with very different payment systems.

While we view our findings as informative in understanding the deep reasons behind the coexistence of money and credit, there few caveats to our analysis. First, while our emphasis on a centralized credit system makes the analysis tractable, this comes at a cost by ruling out distributional issues. This may well be important since the evidence suggests that credit card usage varies across household incomes (SCF (2007), Chatterjee, Corbae, Nakajima, and Rios-Rull (2007)). However, dealing with household income effects entails computational difficulties that our current study does not address. Furthermore, our assumption of a competitive clearing-house for credit abstracts away from efficiency and pricing issues associated with some modern credit systems. Having a more active role for banks and intermediaries to facilitate credit transactions would be a fruitful direction for future work. 


\section{References}

Alvarez, Fernando and Urban Jermann (2000): "Efficiency, Equilibrium, and Asset Pricing with Risk of Default." Econometrica, 68, 775-797.

Andolfatto, David (2013): "Incentive-Feasible Deflation." Journal of Monetary Economics, 60(4), 383-390.

Antinolfi, Gaetano, Costas Azariadis, and James Bullard (2009): "The Optimal Inflation Target in an Economy with Limited Enforcement." Washington University at St. Louis Manuscript.

Arango, Carlos and Varya Taylor (2008): "Merchants' Costs of Accepting Means of Payment: Is Cash the Least Costly?" Bank of Canada Review.

Araujo, Luis and Tai-Wei Hu (2014): "Optimal Monetary Interventions in Credit Markets." Mimeo.

Aruoba, Boragan, Guillaume Rocheteau, and Christopher Waller (2007): "Bargaining and the Value of Money." Journal of Monetary Economics, 54(8), 2636-2655.

Berentsen, Aleksander, Gabriele Camera, and Christopher Waller (2007): "Money, Credit, and Banking." Journal of Economic Theory, 135(1), 171-195.

Bethune, Zachary, Guillaume Rocheteau, and Peter Rupert (2014): "Unemployment and Household Unsecured Debt." Review of Economic Dynamics, 18(1), 77-100.

Bethune, Zachary, Tai-Wei Hu, and Guillaume Rocheteau (2014): "Dynamic Indeterminacy and Welfare in Credit Economies." Mimeo.

Briglevics, Tamas and Scott Schuh (2013): "U.S. Consumer Demand for Cash in the Era of Low Interest Rates and Electronic Payments." Federal Reserve Bank of Boston Working Paper No. 13-23.

Chakravorti, Sujit (2010): "Externalities in Payment Card Networks: Theory and Evidence," Berkeley Electronic Press, vol. 9(2).

Chakravorti, Sujit and Ted To (2007): "A Theory of Credit Cards." International Journal of Industrial Organization, 25(3), 583-595

Chatterjee, Satyajit, Dean Corbae, Makoto Nakajima, and Jose Victor Rios-Rull (2007): “A Quantitative Theory of Unsecured Consumer Credit with Risk of Default." Econometrica, 75(6), $1525-1589$.

Dong, Mei (2011): "Money and Costly Credit." Mimeo.

Federal Reserve (2005): "Consumer Credit." Federal Reserve Statistical Release G-19.

Foster, Kevin, Erik Meijer, Scott Schuh, and Michael Zabek (2011): "The 2009 Survey of Consumer Payment Choice." Federal Reserve Bank of Boston Public Policy Discussion Papers.

Freeman, Scott and Finn E. Kydland (2000): "Monetary Aggregates and Output." American 
Economic Review, vol. 90(5), 1125-1135.

Garcia-Swartz, D.D., R.W. Hahn, and A. Layne-Farrar (2006): "The Move Toward a Cashless Society: A Closer Look at Payment Instrument Economics." Review of Network Economics, vol. 5 (2), 175-198.

Gerdes, Geoffrey (2008): "Recent Payment Trends in the United States." Federal Reserve Bulletin, vol. 94, A75-A106.

Gomis-Porqueras, Pedro and Daniel Sanches (2013): "Optimal Monetary Policy in a Model of Money and Credit." Journal of Money, Credit, and Banking, 45, 4, 7010730.

Gowrisankaran, Gautam and Joanna Stavins (2004): "Network Externalities and Technology Adoption: Lessons from Electronic Payments. RAND Journal of Economics. vol. 35, no. 2, 260-276.

Gu, Chao, Fabrizio Mattesini, and Randall Wright (2014): "Money and Credit Redux." Mimeo.

Hu, Tai-Wei, John Kennan, and Neil Wallace (2009): "Coalition-Proof Trade and the Friedman Rule in the Lagos-Wright Model." Journal of Political Economy, 117(1), 116-137.

Kalai, Ehud (1977): "Proportional Solutions to Bargaining Situations: Interpersonal Utility Comparisons." Econometrica, 45, 1623-1630.

Kahn, Charles and William Roberds (2008): "Credit and Identity Theft." Journal of Monetary Economics.

Kehoe, Timothy and David Levine (1993): "Debt-Constrained Asset Markets." Review of Economic Studies, 60(4), 865-888.

Kehoe, Timothy and David Levine (2001): "Liquidity Constrained Markets Versus Debt Constraint Markets." Econometrica, 69, 575-598.

Kocherlakota, Narayana (1998): "Money Is Memory." Journal of Economic Theory, vol. 81(2), $232-251$.

Kocherlakota, Narayana and Neil Wallace (1998): "Incomplete Record-Keeping and Optimal Payment Arrangements." Journal of Economic Theory, vol. 81(2), 272-289.

Lacker, Jeffrey and Stacey Schreft (1996): "Money and Credit as Means of Payment." Journal of Monetary Economics, 38, 3-23.

Lagos, Ricardo and Guillaume Rocheteau (2008): "Money and Capital as Competing Media of Exchange." Journal of Economic Theory, 142(1), 247-258.

Lagos, Ricardo (2010): "Asset Prices and Liquidity in an Exchange Economy." Journal of Monetary Economics, 57(8), 913-930.

Lester, Benjamin, Andrew Postlewaite, and Randall Wright (2012): "Liquidity, Asset Pricing, and Monetary Policy." Review of Economic Studies, vol. 79(3), 12090-1238. 
Li, Yiting, Guillaume Rocheteau, and Pierre-Olivier Weill (2012): "Liquidity and the Threat of Fraudulent Assets." Journal of Political Economy, vol. 120, 815-846.

Liu, Lucy, Liang Wang, and Randall Wright (2014): "Sticky Prices and Costly Credit." Mimeo.

Nosal, Ed and Guillaume Rocheteau (2011): Money, Payments, and Liquidity. MIT Press.

Roberds, William and Stacey Schreft (2009): "Data Breaches and Identify Theft." Journal of Monetary Economics.

Rochet, Jean-Charles and Jean Tirole (2006): "Two-Sided Markets: A Progress Report." The Rand Journal of Economics, 37(4): 64567.

Rysman, Marc (2009): "The Economics of Two-Sided Markets." Journal of Economic Perspectives, volume 23, 3, 125-143.

Sanches, Daniel and Stephen Williamson (2010): "Money and Credit with Limited Commitment and Theft." Journal of Economic Theory, Volume 145, 1525-1549.

Shi, Shouyong (1996): "Credit and Money in a Search Model with Divisible Commodities." Review of Economic Studies, 63, 627-652.

Telyukova, Irina and Randall Wright (2008): "A Model of Money and Credit, with Application to the Credit Card Debt Puzzle." Review of Economic Studies, 75(2), 629-647.

Telyukova, Irina (2013): "Household Need for Liquidity and the Credit Card Debt Puzzle." Review of Economic Studies, 80(3), 1148-1177.

Townsend, Robert (1989): "Currency and Credit in a Private Information Economy." Journal of Political Economy, 97, 1323-1344.

Wallace, Neil (1998): “A Dictum for Monetary Theory." Federal Reserve Bank of Minneapolis Quarterly Review.

Williamson, Stephen (1987): "Costly Monitoring, Loan Contracts, and Equilibrium Credit Rationing." The Quarterly Journal of Economics, vol. 102(1), pages 135-45.

Wright, Julian (2011): "Why do Firms Accept Credit Cards?" Review of Network Economics, $9(3), 1-8$.

Zhang, Cathy (2014): "An Information-Based Theory of International Currency." Journal of International Economics, 93(2), 286-301. 


\section{Appendix A}

\section{Concavity of Buyer's Objective Function}

The buyer's objective function is

$$
\Psi(z)=-i z+\sigma \theta \Lambda\left[u\left(q^{c}\right)-c\left(q^{c}\right)\right]+\sigma \theta(1-\Lambda)[u(q)-c(q)]
$$

where $q^{c}$ and $q$ are given by $z+\bar{b}=(1-\theta) u\left(q^{c}\right)+\theta c\left(q^{c}\right)$ and $z=(1-\theta) u(q)+\theta c(q)$, respectively, and $\bar{b}$ is given by (17). The partial derivative of the buyer's objective function with respect to the choice of real balances is

$$
\Psi^{\prime}(z)=-i+\sigma \theta \Lambda\left[\frac{u^{\prime}\left(q^{c}\right)-c^{\prime}\left(q^{c}\right)}{\theta c^{\prime}\left(q^{c}\right)+(1-\theta) u^{\prime}\left(q^{c}\right)}\right]+\sigma \theta(1-\Lambda)\left[\frac{u^{\prime}(q)-c^{\prime}(q)}{\theta c^{\prime}(q)+(1-\theta) u^{\prime}(q)}\right],
$$

if $z+\bar{b}<(1-\theta) u\left(q^{*}\right)+\theta c\left(q^{*}\right)$. Consider the case where $z+\bar{b}<(1-\theta) u\left(q^{*}\right)+\theta c\left(q^{*}\right)$ and hence $q^{c}<q^{*}$ and $q<q^{*}$. The second partial derivative is

$$
\Psi^{\prime \prime}(z)=\sigma \theta\left[\Lambda \Delta^{c}+(1-\Lambda) \Delta\right]<0,
$$

where $\Delta^{c}=\frac{u^{\prime \prime}\left(q^{c}\right) c^{\prime}\left(q^{c}\right)-u^{\prime}\left(q^{c}\right) c^{\prime \prime}\left(q^{c}\right)}{\left[\theta c^{\prime}\left(q^{c}\right)+(1-\theta) u^{\prime}\left(q^{c}\right)\right]^{3}}<0$ and $\Delta=\frac{u^{\prime \prime}(q) c^{\prime}(q)-u^{\prime}(q) c^{\prime \prime}(q)}{\left[\theta c^{\prime}(q)+(1-\theta) u^{\prime}(q)\right]^{3}}<0$. Hence for all $(z, \bar{b})$ such that $\bar{b}$ solves $(17)$ and $z+\bar{b}<(1-\theta) u\left(q^{*}\right)+\theta c\left(q^{*}\right)$, the objective function $\Psi(z)$ is strictly concave.

\section{Proof of Lemma 2}

(1) When money is not valued, the flow cost of default is given by

$$
\left.\Omega(\bar{b})\right|_{\phi=0}=\sigma \Lambda \theta S(\bar{b})
$$

(a). If $\bar{b}=0,\left.\Omega(0)\right|_{\phi=0}=\sigma \Lambda \theta S(0)=0$.

(b). The slope of $\left.\Omega(\bar{b})\right|_{\phi=0}$ at $\bar{b}=0$ is

$$
\begin{aligned}
\left.\Omega^{\prime}(0)\right|_{\phi=0} & =\sigma \theta \Lambda S^{\prime}(0) \\
& =\frac{\sigma \Lambda \theta}{1-\theta}>0 .
\end{aligned}
$$

(c). The slope of $\left.\Omega(\bar{b})\right|_{\phi=0}$ is given by

$$
\left.\Omega^{\prime}(\bar{b})\right|_{\phi=0}=\sigma \theta \Lambda S^{\prime}(\bar{b})>0
$$


for all $\bar{b}<\bar{b}_{1}$. Otherwise, $\left.\Omega^{\prime}(\bar{b})\right|_{\phi=0}=0$.

(d). $\left.\Omega(\bar{b})\right|_{\phi=0}$ is strictly increasing and concave for all $\bar{b}<\bar{b}_{1}$ since

$$
\left.\Omega^{\prime}(\bar{b})\right|_{\phi=0}=\sigma \theta \Lambda S^{\prime}(\bar{b})>0
$$

and

$$
\left.\Omega^{\prime \prime}(\bar{b})\right|_{\phi=0}=\sigma \theta \Lambda S^{\prime \prime}(\bar{b})<0
$$

for all $\bar{b}<\bar{b}_{1}$. Otherwise, $\left.\Omega(\bar{b})\right|_{\phi=0}$ is constant at $\sigma \theta \Lambda S^{*}$ since $\left.\Omega^{\prime}(\bar{b})\right|_{\phi=0}=0$ for all $\bar{b} \geq \bar{b}_{1}$.

(2) When money is valued, the flow cost of default is given by

$$
\left.\Omega(\bar{b})\right|_{\phi>0} \equiv \max _{z>0}\{-i z+\sigma \theta[(1-\Lambda) S(z)+\Lambda S(z+\bar{b})]\}-\max _{\widetilde{z}>0}\{-i \widetilde{z}+\sigma \theta S(\widetilde{z})\}
$$

(a). If $\bar{b}=0$, then $z=\widetilde{z}$ since

$$
-i z+\sigma \theta S(z)=-i \widetilde{z}+\sigma \theta S(\widetilde{z})
$$

Consequently, $\left.\Omega(0)\right|_{\phi>0}=0$.

(b). The slope of $\left.\Omega(\bar{b})\right|_{\phi>0}$ at $\bar{b}=0$ is

$$
\begin{aligned}
\left.\Omega^{\prime}(0)\right|_{\phi>0} & =\sigma \theta \Lambda S^{\prime}(z) \\
& =i \Lambda>0,
\end{aligned}
$$

where we have used the fact that at $\bar{b}=0$, a necessary condition for valued money is $i=\sigma \theta S^{\prime}(z)$. Moreover, notice that $\left.\Omega^{\prime}(0)\right|_{\phi>0}<\left.\Omega^{\prime}(0)\right|_{\phi=0}$ if and only if $i<\frac{\sigma \theta}{1-\theta}$.

(c). The slope of $\left.\Omega(\bar{b})\right|_{\phi>0}$ is given by

$$
\left.\Omega^{\prime}(\bar{b})\right|_{\phi>0}=\sigma \theta \Lambda S^{\prime}(z+\bar{b})>0,
$$

for all $\bar{b}<\bar{b}_{1}-\bar{z}$.

(d). $\left.\Omega(\bar{b})\right|_{\phi>0}$ is strictly increasing and concave for all $\bar{b}<\bar{b}_{1}-\bar{z}$ since

$$
\left.\Omega^{\prime}(\bar{b})\right|_{\phi>0}=\sigma \theta \Lambda S^{\prime}(z+\bar{b})>0
$$

and

$$
\left.\Omega^{\prime \prime}(\bar{b})\right|_{\phi>0}=\sigma \theta \Lambda S^{\prime \prime}(z+\bar{b})<0
$$

for all $\bar{b}<\bar{b}_{1}-\bar{z}$. 
Figure 19: Determination of $\widetilde{i}$ when $\Lambda \in(\bar{\Lambda}, 1)$

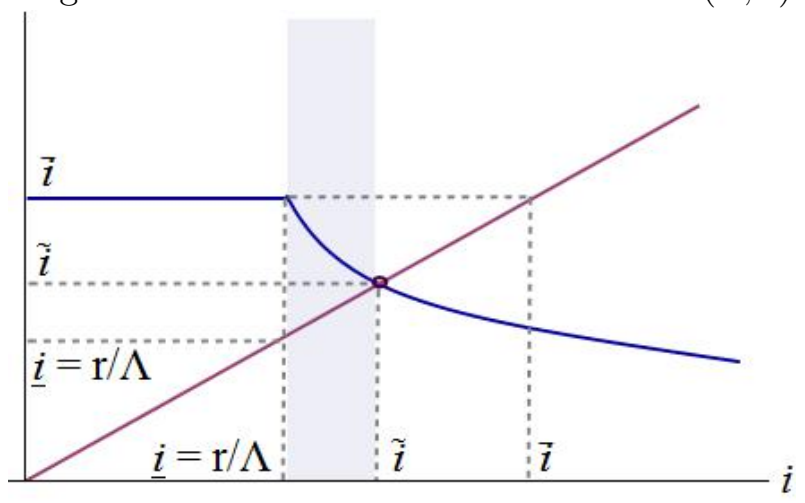

\section{Proof of Lemma 3}

(1) Suppose $i<\hat{i}$. Then $\bar{b}_{0}$ does not exist and money is valued for any $\bar{b} \geq 0$. To verify, we check the conditions for money to be valued given $\bar{b}=0$ and $\bar{b}>0$. First, money is valued given $\bar{b}=0$ if and only if

$$
i<\frac{\sigma \theta}{1-\theta} \equiv \bar{i}
$$

Since $\widehat{i}<\bar{i}$ whenever $\Lambda \in(0,1), i<\widehat{i}$ implies the condition $i<\bar{i}$ is satisfied. Second, money is valued given $\bar{b}>0$ if and only if $i<\widetilde{i}$ where $\tilde{i}$ solves

$$
\widetilde{i}=\frac{\sigma(1-\Lambda) \theta}{1-\theta}+\sigma \Lambda \theta S^{\prime}[\bar{b}(\widetilde{i}, \Lambda)]
$$

Similarly, since $\widehat{i}<\widetilde{i}$ whenever $\Lambda \in(0,1), i<\widehat{i}$ implies the condition $i<\widetilde{i}$ is satisfied.

(2) Suppose $i \geq \widehat{i}$. By construction, money is valued if and only if $\bar{b}<\bar{b}_{0}$.

\section{Proof of Proposition 1}

(1) The derivation of the necessary condition for a money and credit equilibrium, $i \in(\underline{i}, \widetilde{i})$ appears in the main text. Given $\Lambda \in(0,1)$, that a pure monetary equilibrium exists whenever there is an equilibrium with both money and credit can be verified by noting the condition for a monetary equilibrium, $i<\bar{i}$, is always satisfied if $i \in(\underline{i}, \widetilde{i})$ and that there is always a solution to (17) with $\bar{b}=0$. See also Figure (19). To show that a pure credit equilibrium will also exist when $i \in(\underline{i}, \widetilde{i})$, recall that the necessary condition for credit given $z=\widetilde{z}=0$ is $r<\sigma \Lambda \frac{\theta}{1-\theta}$, which is equivalent to the condition $\Lambda>\bar{\Lambda}$ or $\underline{i}<\bar{i}$. 
(2) When $\Lambda=1$, here we show that a money and credit equilibrium does not exist for any $i \neq r$.

Given $\Lambda=1$ and money is valued, (13) and (14) imply $i=\sigma \theta S^{\prime}[q(z+\bar{b})]=\sigma \theta S^{\prime}[q(\widetilde{z})]$, or $q(z+\bar{b})=q(\widetilde{z})$. Then since $z+\bar{b}=\widetilde{z}=(1-\theta) u(q)+\theta c(q)$ from the bargaining solution, the right side of the debt limit (17) becomes $-i[z-\widetilde{z}]=-i[\widetilde{z}-\bar{b}-\widetilde{z}]=i \bar{b}$. Consequently, (17) implies that $r \bar{b}=i \bar{b}$, or $\bar{b}=0$ if $i \neq r$. Hence, when $\Lambda=1$ and $i \neq r$, buyers obtain the same surplus whether or not they default, in which case there cannot exist a positive debt limit that supports voluntary debt repayment. If $\Lambda=1$ and $i=r$, any $\bar{b} \in\left[0, \bar{b}_{0}\right]$ is a solution.

(a). If $r<i<\bar{i}$ or $i \leq r<\bar{i}$, it is straightforward to verify a pure monetary equilibrium coexists with a pure credit equilibrium. First, a pure monetary exists if $i<\bar{i}$ for all $\Lambda$, which is satisfied. Second, a pure credit equilibrium exists if $r<\bar{i}$ for $\Lambda=1$, which is also satisfied.

(b). If $i<\bar{i}$ and $r \geq \bar{i}$, money is valued given there is no credit and the necessary condition for a pure credit equilibrium is violated, and hence credit is not feasible.

(c). If $i \geq \bar{i}$ and $r<\bar{i}$, credit is feasible since the necessary condition for a pure credit equilibrium is satisfied, but money is not valued.

(d). If $i=r<\bar{i}$, the conditions for a pure monetary equilibrium and a pure credit equilibrium are satisfied. In addition, given money is valued, the debt limit is indeterminate since there are a continuum of debt limits, $\bar{b} \in\left[0, \bar{b}_{0}\right]$, that satisfy (17).

\section{Proof of Proposition 2}

To prove Proposition 2, we verify some properties of the thresholds $\underline{i}=\frac{r}{\Lambda}, \bar{i}=\frac{\sigma \theta}{1-\theta}$, and $\widetilde{i}=$ $(1-\Lambda) \bar{i}+\sigma \theta \Lambda S^{\prime}[\bar{b}(\widetilde{i}, \Lambda)]$ given by Figure (19).

1. When $\Lambda \in[0, \bar{\Lambda}), \widetilde{i}=\bar{i}$.

2. When $\Lambda=\bar{\Lambda}, \underline{i}=\widetilde{i}=\bar{i}$.

3. When $\Lambda \in(\bar{\Lambda}, 1), \underline{i}<\widetilde{i}<\bar{i}$.

4. When $\Lambda=1, \underline{i}=\widetilde{i}$ at $i=r$.

5. When $\Lambda>\bar{\Lambda}, \widetilde{i}$ is a decreasing function of $\Lambda$ :

$$
\frac{\widetilde{d}}{d \Lambda}=\frac{\left.\left.-\bar{i}+\sigma \theta \Lambda S^{\prime \prime}[\bar{b}(\widetilde{i}, \Lambda)] \frac{d \bar{b}}{d \Lambda}+\sigma \theta S^{\prime}[\bar{b} \widetilde{i}, \Lambda)\right]\right]}{\left.1-\sigma \theta \Lambda S^{\prime \prime}[\bar{b} \widetilde{i}, \Lambda)\right] \frac{d \bar{b}}{d i}}<0
$$

since $S^{\prime}(\cdot)>0, S^{\prime \prime}(\cdot)<0, \frac{d \bar{b}}{d \Lambda}>0$, and $\frac{d \bar{b}}{d i}>0$. 
When $\Lambda<\bar{\Lambda}$ (or, equivalently $\underline{i}>\bar{i}$ ), we have $\widetilde{i}=(1-\Lambda) \bar{i}+\sigma \theta \Lambda S^{\prime}(0)=\bar{i}$. Next, we verify that given $\bar{b}>0, \underline{i} \leq \widetilde{i}$ if and only if $\Lambda>\bar{\Lambda}$, or $\underline{i}<\bar{i}$ :

$$
\begin{aligned}
& \underline{i} \leq(1-\Lambda) \bar{i}+\sigma \theta \Lambda S^{\prime}[\bar{b}(\widetilde{i}, \Lambda)] \\
& \underline{i}<(1-\Lambda) \bar{i}+\sigma \theta \Lambda S^{\prime}(0), \\
& \underline{i}<\bar{i} .
\end{aligned}
$$

At $\Lambda=1$ however, we know a money and credit equilibrium ceases to exist for any $i \neq r$. Given $\bar{b}, z=0$ if and only if $i \geq \widetilde{i}$ and $z>0$ if and only if $i<\widetilde{i}$, where $\widetilde{i}$ solves

$$
\widetilde{i}=\sigma \theta S^{\prime}[\bar{b}(\widetilde{i}, 1)]
$$

Figure 10 shows $\widetilde{i}=\underline{i}=r$, in which case $\underline{i}=\widetilde{i}<\bar{i}$. At $i=r$, we therefore have $\widetilde{i}=\underline{i}$, meaning that the condition for a money and credit equilibrium collapses to a single point, $i=r$.

\section{Proof of Lemma 4}

First, to show the debt limit is increasing in $\Lambda$, we differentiate $r \bar{b}=\Omega(\bar{b})$ to obtain

$$
r d \bar{b}=\sigma \theta\left[-S(z) d \Lambda+S(z+\bar{b}) d \Lambda+\Lambda S^{\prime}(z+\bar{b}) d \bar{b}\right]
$$

When money is not valued,

$$
\left.\frac{d \bar{b}}{d \Lambda}\right|_{\phi=0}=\frac{\sigma \theta S(\bar{b})}{r-\sigma \theta \Lambda S^{\prime}(\bar{b})}>0
$$

for all $\bar{b} \in\left(0, \bar{b}_{1}\right)$ since $r>\sigma \theta \Lambda S^{\prime}(\bar{b})$ when $\bar{b}>0$. Similarly when money is valued,

$$
\left.\frac{d \bar{b}}{d \Lambda}\right|_{\phi>0}=\frac{\sigma \theta[S(z+\bar{b})-S(z)]}{r-\sigma \theta \Lambda S^{\prime}(z+\bar{b})}>0
$$

for all $\bar{b} \in\left(0, \bar{b}_{0}\right)$ since $S(z+\bar{b})>S(z)$ and $r>\sigma \theta \Lambda S^{\prime}(z+\bar{b})$.

Next, we verify that the debt limit is a strictly convex function of $\Lambda$ for all $\bar{b}<\bar{b}_{1}$ :

$$
\left.\frac{d^{2} \bar{b}}{d \Lambda^{2}}\right|_{\phi>0}=\frac{(\sigma \theta)^{2}[S(z+\bar{b})-S(z)] S^{\prime}(z+\bar{b})}{\left[r-\sigma \theta \Lambda S^{\prime}(z+\bar{b})\right]^{2}}>0,
$$

since $S^{\prime}(z+\bar{b})>0$ when $\bar{b}<\bar{b}_{1}$. The derivative when money is not valued is similar but with $z=0$.

Finally, $\bar{b}$ is linear in $\Lambda$ when $\bar{b} \geq \bar{b}_{1}:\left.\frac{d \bar{b}}{d \Lambda}\right|_{\bar{b} \geq \bar{b}_{1}}>0$ and $\left.\frac{d^{2} \bar{b}}{d \Lambda^{2}}\right|_{\bar{b} \geq \bar{b}_{1}}=0$ since $S^{\prime}\left(\bar{b}_{1}\right)=0$. 


\section{Proof of Lemma 5}

To prove Lemma 5, we make use of the fact that the seller's benefit of investing is increasing in the measure of sellers that invest. With Kalai bargaining, the seller's benefit of investing is

$$
\bar{\kappa}(\bar{b})=\sigma(1-\theta)[S(z+\bar{b})-S(z)] .
$$

Hence, for a given debt limit and choice of real balances by buyers, we have

$$
\frac{\partial \bar{\kappa}(\bar{b})}{\partial \Lambda}=\sigma(1-\theta)\left\{S^{\prime}(z+\bar{b}) \frac{d \bar{b}}{d \Lambda}+\left[S^{\prime}(z+\bar{b})-S^{\prime}(z)\right] \frac{d z}{d \bar{b}}\right\}
$$

Recall $S(\cdot)$ is increasing and concave, and from Lemma 4, the debt limit is increasing in $\Lambda$. If money is valued, then for all $\bar{b}<\bar{b}_{0}$,

$$
\left.\frac{\partial \bar{\kappa}(\bar{b})}{\partial \Lambda}\right|_{\phi>0}=\sigma(1-\theta)\{\underbrace{S^{\prime}(z+\bar{b})}_{(+)} \underbrace{\frac{d \bar{b}}{d \Lambda}}_{(+)}+\underbrace{\left[S^{\prime}(z+\bar{b})-S^{\prime}(z)\right]}_{(-)} \underbrace{\frac{d z}{d \bar{b}}}_{(-)}\}>0,
$$

Similarly, if money is not valued, then for all $\bar{b}<\bar{b}_{1}$,

$$
\left.\frac{\partial \bar{\kappa}(\bar{b})}{\partial \Lambda}\right|_{\phi=0}=\sigma(1-\theta) \underbrace{S^{\prime}(\bar{b})}_{(+)} \underbrace{\frac{d \bar{b}}{d \Lambda}}_{(+)}>0
$$

and $\left.\frac{\partial \bar{\kappa}(\bar{b})}{\partial \Lambda}\right|_{\phi=0}=0$ otherwise. Hence, for a given debt limit and choice of real balances by buyers, the seller's benefit of investing is increasing in $\Lambda$.

We now turn to the proof of Lemma 5 proper. In the following, we consider the case where $i>\widehat{i}$; the case where $i<\widehat{i}$ is similar except the threshold $\bar{b}_{0}$ does not exist and should be replaced with $\bar{b}_{1}-\bar{z}$.

First, notice when $\bar{b}=0$, the seller's expected benefit of investing is zero, whether or not money is valued: $\left.\bar{\kappa}(0)\right|_{\phi=0}=\left.\bar{\kappa}(0)\right|_{\phi>0}=0$. Consequently, no sellers will invest: $\Lambda=0$. For $\bar{b}>0$, we now consider separately the cases when (1) money is not valued $(\phi=0)$ and (2) money is valued $(\phi>0)$. We also show (3) $\left.\Lambda(\bar{b})\right|_{\phi=0}>\left.\Lambda(\bar{b})\right|_{\phi>0}$ for a given $\bar{b}<\bar{b}_{0}$, and $\left.\left.\Lambda(\bar{b})\right|_{\phi=0} \rightarrow \Lambda(\bar{b})\right|_{\phi>0}$ as $\bar{b} \rightarrow \bar{b}_{0}$.

(1) When money is not valued, the seller's expected benefit of investing when $\bar{b} \in\left(0, \bar{b}_{1}\right)$ is a 
strictly increasing and concave function of the debt limit:

$$
\begin{aligned}
\left.\bar{\kappa}^{\prime}(\bar{b})\right|_{\phi=0} & =\sigma(1-\theta) S^{\prime}(\bar{b})>0, \\
\left.\bar{\kappa}^{\prime \prime}(\bar{b})\right|_{\phi=0} & =\sigma(1-\theta) S^{\prime \prime}(\bar{b})<0,
\end{aligned}
$$

since $S^{\prime}(\bar{b})>0$ and $S^{\prime \prime}(\bar{b})<0$ for $\bar{b} \in\left(0, \bar{b}_{1}\right)$.

When $\bar{b}=\bar{b}_{1}$, buyers can borrow enough to purchase the first-best. In that case, the seller's benefit of investing is at its maximum:

$$
\bar{\kappa}_{\max } \equiv \sigma(1-\theta) S^{*}
$$

where $S^{*} \equiv u\left(q^{*}\right)-c\left(q^{*}\right)$. Sellers with $\kappa<\bar{\kappa}_{\max }$ will invest, and those with $\kappa>\bar{\kappa}_{\max }$ will not invest. Let $\Lambda_{s}$ denote the aggregate measure of sellers that invest when $\bar{b}=\bar{b}_{1}$. Since $\frac{d \bar{\kappa}_{\max }}{d \bar{b}}=0$, the aggregate measure of sellers who invest when $\bar{b}>\bar{b}_{1}$ is also $\Lambda_{s} \leq 1$.

(2) When money is valued, the expected benefit of investing is

$$
\left.\bar{\kappa}(\bar{b})\right|_{\phi>0}=\sigma(1-\theta)[S(z+\bar{b})-S(z)]
$$

which is increasing in debt limit for all $\bar{b} \in\left(0, \bar{b}_{0}\right)$. To verify, differentiate to obtain

$$
\left.\bar{\kappa}^{\prime}(\bar{b})\right|_{\phi>0}=\sigma(1-\theta)\left\{S^{\prime}(z+\bar{b})+\left[S^{\prime}(z+\bar{b})-S^{\prime}(z)\right] \frac{d z}{d \bar{b}}\right\}>0,
$$

where $S^{\prime}(z+\bar{b})<S^{\prime}(z)$ since $S$ is concave and

$$
\frac{d z}{d \bar{b}}=-\left[1+\frac{(1-\Lambda) S^{\prime \prime}(z)}{\Lambda S^{\prime \prime}(z+\bar{b})}\right]^{-1}<0
$$

since $S^{\prime \prime}(z)<0$ and $S^{\prime \prime}(z+\bar{b})<0$ for all $\bar{b} \in\left(0, \bar{b}_{0}\right)$. Consequently, $\left.\frac{d \bar{\kappa}}{d \bar{b}}\right|_{\phi>0}>0$.

(3) For all $\bar{b} \in\left(0, \bar{b}_{0}\right),\left.\bar{\kappa}(\bar{b})\right|_{\phi=0}>\left.\bar{\kappa}(\bar{b})\right|_{\phi>0}$ since $S(\bar{b})>S(z+\bar{b})-S(z)$ given the concavity of $S(\cdot)$. At $\bar{b}=\bar{b}_{0}$, we have $z=0$ and hence $\left.\bar{\kappa}(\bar{b})\right|_{\phi=0}=\left.\bar{\kappa}(\bar{b})\right|_{\phi>0}$.

\section{Proof of Proposition 3}

We prove Proposition 3 in two steps.

(1) Given the assumptions made on the cost function, we first show that for a given debt limit and value of money, there exists an equilibrium where $\Lambda$ sellers invest to access the record-keeping technology. To show that an equilibrium exists, we make use of the fact that the seller's benefit 
of investing is increasing in the measure of sellers that invest (see the proof of Lemma 5). This immediately implies that it is never the case that a seller invests when a fraction $\Lambda^{\prime}$ other sellers invest but not when $\Lambda^{\prime \prime}>\Lambda^{\prime}$ others invest. Since we assume that $\kappa$ is zero for a positive measure of sellers and $\kappa$ is arbitrarily high for a positive measure of sellers, there will always be some sellers that invest and some other sellers who do not. Aggregating across all sellers with respect to $F(\kappa)$ then implies that we can always find an equilibrium where $\Lambda \in(0,1)$ sellers invest.

(2) Once we determine $\Lambda$, we know from Section 4 that we can find an equilibrium debt limit. All other endogenous variables can then easily be obtained as before.

\section{Welfare in a Money and Credit Equilibrium}

Steady-state welfare in a money and credit equilibrium is given by

$$
\mathcal{W}^{m c}=\sigma[\Lambda S(z+\bar{b})+(1-\Lambda) S(z)]-k \text {. }
$$

To ease computation, we begin by taking $\Lambda \in(0,1)$ is given. Totally differentiating $\mathcal{W}^{m c}$ with respect to $i$, we obtain:

$$
\frac{d \mathcal{W}^{m c}}{d i}=\sigma \Lambda S^{\prime}(z+\bar{b})[\underbrace{\frac{d z}{d i}}_{(-)}+(\underbrace{\frac{d z}{d \bar{b}}}_{(-)}+1) \underbrace{\frac{d \bar{b}}{d i}}_{(+)}]+\sigma(1-\Lambda) S^{\prime}(z) \underbrace{\frac{d z}{d i}}_{(-)},
$$

where

$$
\begin{gathered}
\frac{d z}{d \bar{b}}=-\left[1+\frac{(1-\Lambda) S^{\prime \prime}(z)}{\Lambda S^{\prime \prime}(z+\bar{b})}\right]^{-1} \in(-1,0), \\
\frac{d z}{d i}=\left[\sigma \theta\left[(1-\Lambda) S^{\prime \prime}(z)+\Lambda S^{\prime \prime}(z+\bar{b})\right]\right]^{-1}<0, \\
\frac{d \widetilde{z}}{d i}=\left[\sigma \theta S^{\prime \prime}(\widetilde{z})\right]^{-1}<0,
\end{gathered}
$$

and

$$
\frac{d \bar{b}}{d i}=\frac{\widetilde{z}-z}{r-\sigma \theta \Lambda S^{\prime}(z+\bar{b})}>0,
$$

since $S^{\prime \prime}(\cdot)<0, \widetilde{z}>z$ and $r-\sigma \theta \Lambda S^{\prime}(z+\bar{b})>0$.

Hence, a necessary and sufficient condition for $\frac{d \mathcal{W}^{m c}}{d i}<0$ is

$$
\frac{d z}{d i}+\left(\frac{d z}{d \bar{b}}+1\right) \frac{d \bar{b}}{d i}<0
$$


Let $\frac{d z}{d \bar{b}}=-a$ where $a \equiv\left[1+\frac{(1-\Lambda) S^{\prime \prime}(z)}{\Lambda S^{\prime \prime}(z+\bar{b})}\right]^{-1}$. Consequently,

$$
\frac{d \mathcal{W}^{m c}}{d i}=\sigma \Lambda S^{\prime}(z+\bar{b})\left[\frac{d z}{d i}+(1-a) \frac{d \bar{b}}{d i}\right]+\sigma(1-\Lambda) S^{\prime}(z) \frac{d z}{d i}
$$

and

$$
\begin{aligned}
\frac{d \mathcal{W}^{m c}}{d i} & <0 \\
& \Longleftrightarrow \frac{d z}{d i}+(1-a) \frac{d \bar{b}}{d i}<0 \\
& \Longleftrightarrow \frac{d z}{d \bar{b}}<a-1 \\
& \Longleftrightarrow a>\frac{1}{2}
\end{aligned}
$$

The condition $a>\frac{1}{2}$ is satisfied when $\frac{(1-\Lambda) S^{\prime \prime}(z)}{\Lambda S^{\prime \prime}(z+\bar{b})}<1$ or

$$
\Lambda>\frac{S^{\prime \prime}(z)}{S^{\prime \prime}(z)+S^{\prime \prime}(z+\bar{b})} \equiv \widehat{\Lambda}
$$

Therefore, welfare in a money and credit equilibrium is decreasing with inflation when $a \in\left(\frac{1}{2}, 1\right)$, or equivalently when $\Lambda>\widehat{\Lambda}$.

Notice when $\Lambda$ is close to $0, \frac{d \mathcal{W}^{m c}}{d i} \approx \sigma S^{\prime}(z) \frac{d z}{d i}<0$.

Finally, when $a<\frac{1}{2}$, or $\Lambda<\widehat{\Lambda}$,

$$
\sigma(1-\Lambda) S^{\prime}(z) \frac{d z}{d i}<0
$$

and

$$
\sigma \Lambda S^{\prime}(z+\bar{b})\left[\frac{d z}{d i}+(1-a) \frac{d \bar{b}}{d i}\right]>0
$$

In that case, the sign of $\frac{d \mathcal{W}^{m c}}{d i}$ is indeterminate.

\section{Welfare Comparison in a Money and Credit Equilibrium vs. Pure Credit Equilibrium}

Here we show that $\mathcal{W}^{m c} \geq \mathcal{W}^{c}$ for all $i \in(\underline{i}, \widetilde{i})$ so long as $k>0$ and the threshold $i_{c}$ exists, that is if $\mathcal{W}^{m}>\mathcal{W}^{c}$ at $i=0$ and $\mathcal{W}^{m}<\mathcal{W}^{c}$ at $i=\widetilde{i}$.

First, notice that at $i=0$, we always have $\mathcal{W}^{m}(0)>\mathcal{W}^{c}(0)$ for any $k>0$. Next, at $i=\underline{i}$, credit is not feasible given money is valued. Consequently, $\mathcal{W}^{m c}(\underline{i})=\sigma S(z)=\mathcal{W}^{m}$. Hence at 
$i=\underline{i}, \mathcal{W}^{m c} \geq \mathcal{W}^{c}$. Similarly, at $i=\widetilde{i}$, money is not valued given there is credit. Consequently, $\mathcal{W}^{m c}(\widetilde{i})=\sigma \Lambda S(\bar{b})-k=\mathcal{W}^{c}$. Hence at $i=\widetilde{i}, \mathcal{W}^{m c}=\mathcal{W}^{c}$.

\section{Appendix B}

\section{Endogenous Limit on Tax Liabilities}

In this section, we determine the size of the tax obligation that individuals are willing to honor voluntarily. The idea is that the Friedman rule may be infeasible since it requires taxation and individuals may choose to renege on tax payment if it is too high.

The timing of events in the CM is as in Andolfatto (2013). First, an agent decides whether to repay his debt, $b$. We assume that defaulters get caught with probability one, though one can relax this assumption. If the agent repays his debt, he then decides to pay his taxes. If taxes are repaid, agents trade $x, y$ and $z$ in the CM as before. Defaulters in the first or second stages are punished by being excluded from future trades, and the size of the loan, $b$, and lump-sum transfer, $T$, are determined endogenously.

We solve by backwards induction and begin with the decision to honor tax obligations. In order for agents to repay the tax, their payoff from doing so must exceed the payoff from not trading in the DM:

$$
W^{b}(z) \geq z+\beta V^{b}(0) .
$$

In that case, a buyer who reneges on his tax obligations simply consumes his real balances, $z$, and exits without accumulating money. This can be reduced to

$$
T+\max _{z \geq 0}\left\{-\gamma z+\beta V^{b}(z)\right\} \geq \beta W^{b}(0) .
$$

After simplification, the tax payment constraint becomes

$$
T+\max _{z \geq 0}\left\{-\gamma z+\beta\left[\sigma(1-\Lambda) \theta[u(q)-c(q)]+\sigma \Lambda \theta\left[u\left(q^{c}\right)-c\left(q^{c}\right)\right]+z\right]\right\} \geq 0
$$

where $T=(\gamma-1) \phi M<0$ when the money supply is contracting. Therefore, the repayment constraint takes the form of an upper bound on the level of taxes $-T$ :

$$
-T \leq \beta \max _{z \geq 0}\left\{-i z+\sigma(1-\Lambda) \theta[u(q)-c(q)]+\sigma \Lambda \theta\left[u\left(q^{c}\right)-c\left(q^{c}\right)\right]\right\} .
$$

Since the lump-sum transfer in the $\mathrm{CM}$ is $T=(\gamma-1) \phi M$, the repayment constraint can equivalently 
be formulated as a lower bound on the deflation rate:

$$
\gamma \geq-\beta(\phi M)^{-1} \max _{z \geq 0}\left\{-i z+\sigma(1-\Lambda) \theta[u(q)-c(q)]+\sigma \Lambda \theta\left[u\left(q^{c}\right)-c\left(q^{c}\right)\right]\right\}+1 \equiv \underline{\gamma}_{d} .
$$

In order for tax repayment to be incentive compatible, the rate of money growth must be $\gamma \in\left(\underline{\gamma}_{d}, 1\right)$.

\section{Permanent Autarky as Punishment for Default}

Here we depart from our assumption that a buyer who defaults on debt repayment can still use money, and assume instead that a defaulter is punished with permanent autarky.

As before, the borrowing limit, $\bar{b}$, is determined in order to satisfy the buyer's incentive constraint to voluntarily repay his debt in the $\mathrm{CM}$, or

$$
W^{b}(z,-b) \geqslant \widehat{W}^{b}(z)
$$

where $W^{b}(z,-b)$ is the value function of a buyer who chooses to repay his debt at the beginning of the CM, and $\widehat{W}^{b}(z)$ is the value function of a buyer who chooses to default. By the linearity of $W^{b}$, the value function of a buyer who repays his debt in the $\mathrm{CM}$ is

$$
W^{b}(z,-b)=z-b+W^{b}(0,0) .
$$

On the other hand, the value function of a buyer who defaults, $\widehat{W}^{b}(z)$ must satisfy

$$
\widehat{W}^{b}(z)=z+\widehat{W}^{b}(0)
$$

since by defaulting, he is excluded to permanent autarky and can no longer trade in the DM. As a result, a buyer will repay his debt if

$$
\begin{aligned}
W^{b}(z,-b)-\widehat{W}^{b}(z) & \geq 0, \\
W^{b}(0,0)-\widehat{W}^{b}(0) & \geq b, \\
\bar{b} & \geq b,
\end{aligned}
$$

where $\bar{b} \equiv W^{b}(0,0)-\widehat{W}^{b}(0)$ is the endogenous debt limit determined such that buyers will always repay their debt. To solve for the equilibrium value of $\bar{b}$, we determine $W^{b}(0,0)-\widehat{W}^{b}(0)$. The 
value functions of a buyer who does not default in the CM can be rewritten as

$$
\begin{aligned}
W^{b}(0,0) & =T+\max _{z \geq 0}\left\{-\gamma z+\beta V^{b}(z)\right\} \\
& =T+\max _{z \geq 0}\left\{-\gamma z+\beta\left[\sigma(1-\Lambda) \theta S(z)+\sigma \Lambda \theta S(z+\bar{b})+z+W^{b}(0,0)\right]\right\},
\end{aligned}
$$

where $S(z) \equiv u[q(z)]-c[q(z)]$ is the total trade surplus when sellers only accept money, and $S(z+\bar{b}) \equiv u[q(z+\bar{b})]-c[q(z+\bar{b})]$ is the total trade surplus when both money and credit are accepted. Rearranging and dividing both sides of the equality by $\beta$ results in

$$
\frac{(1-\beta)}{\beta} W^{b}(0,0)=\frac{T}{\beta}+\max _{z \geq 0}\left\{-\frac{(\gamma-\beta)}{\beta} z+\sigma \theta[(1-\Lambda) S(z)+\Lambda S(z+\bar{b})]\right\} .
$$

However, the value function of a buyer who defaults in the CM is

$$
\begin{aligned}
\widehat{W}^{b}(0) & =T+\beta \widehat{V}^{b}(0) \\
& =T+\beta \widehat{W}^{b}(0),
\end{aligned}
$$

since by defaulting, a buyer can no longer use money nor credit. Rearranging and dividing both sides of the equality by $\beta$ results in

$$
\frac{(1-\beta)}{\beta} \widehat{W}^{b}(0)=\frac{T}{\beta}
$$

Therefore, the debt limit, $\bar{b}$, must satisfy

$$
\frac{(1-\beta)}{\beta} \bar{b}=\frac{(1-\beta)}{\beta}\left[W^{b}(0,0)-\widehat{W}^{b}(0)\right]
$$

Substituting in the expressions for $W^{b}(0,0)$ and $\widehat{W}^{b}(0)$ then leads to the following expression for $\bar{b}$ :

$$
r \bar{b}=\max _{z \geq 0}\{-i z+\sigma \theta[(1-\Lambda) S(z)+\Lambda S(z+\bar{b})]\} \equiv \widehat{\Omega}(\bar{b})
$$

where $r=\frac{1-\beta}{\beta}$. In contrast with our baseline assumption that a defaulter can still use money, the cost of default under permanent autarky, $\widehat{\Omega}(\bar{b})$ is larger than the cost of default assuming monetary trades are still allowed, $\Omega(\bar{b})$. 


\section{Appendix C}

\section{Kalai vs. Nash Bargaining}

In the main text, we assume the terms of trade in the DM are determined according to the socalled proportional bargaining solution due to Kalai (1977). While the proportional solution has some desirable properties- namely, Pareto efficiency and strong monotonicity (no agent in the pair is made worse-off if additional alternatives are made available to them)- it is not scale invariant. Here we consider an alternative bargaining protocol, the generalized Nash solution, that is Pareto efficient, scale invariant, but not strongly monotonic. ${ }^{24}$

We can generalize our analysis from the main text by considering a general payment function $\omega(\cdot)$ for a DM match, which nests both Kalai and Nash solutions. The Kalai solution maximizes the buyer's surplus, $u(q)-d-b$ subject to $u(q)-d-b=\theta[u(q)-c(q)]$ and $d+b \leq z+\bar{b}$. If the sellers accepts credit, the transfer of wealth from the buyer to seller is

$$
\omega\left(q^{c}\right)=\theta c\left(q^{c}\right)+(1-\theta) u\left(q^{c}\right)
$$

where $q^{c} \equiv q(z+\bar{b})$. If the sellers does not accept credit, then the transfer of wealth is

$$
\omega(q)=\theta c(q)+(1-\theta) u(q)
$$

The generalized Nash solution maximizes the so-called Nash product, $[u(q)-d-b]^{\theta}[-c(q)+$ $d+b]^{1-\theta}$ subject to $d+b \leq z+\bar{b}$. If the sellers accepts credit, the transfer of wealth from the buyer to seller is

$$
\omega\left(q^{c}\right)=\frac{\theta u^{\prime}\left(q^{c}\right) c\left(q^{c}\right)+(1-\theta) c^{\prime}\left(q^{c}\right) u\left(q^{c}\right)}{\theta u^{\prime}\left(q^{c}\right)+(1-\theta) c^{\prime}\left(q^{c}\right)}
$$

where $q^{c} \equiv q(z+\bar{b})$. If the sellers does not accept credit, then the transfer of wealth is

$$
\omega(q)=\frac{\theta u^{\prime}(q) c(q)+(1-\theta) c^{\prime}(q) u(q)}{\theta u^{\prime}(q)+(1-\theta) c^{\prime}(q)} .
$$

For both Kalai and Nash bargaining, the terms of trade only depend on the buyer's total wealth, $z+\bar{b}$, and not the composition of the buyer's portfolio. The two solutions are identical if $\theta=1$, or under a buyer-take-all bargaining solution. However for $\theta \in(0,1)$, the solutions are generally different.

In any case, both solutions take the following form. If the seller accepts credit, then $q^{c}=$

\footnotetext{
${ }^{24}$ Aruoba, Rocheteau, and Waller (2007) offer a more detailed analysis of the Nash and Kalai bargaining solutions and discuss the implications for monetary equilibrium and efficiency.
} 
$\omega^{-1}(z+\bar{b})<q^{*}$ if $z+\bar{b} \leq \omega\left(q^{*}\right)$ and $q^{c}=q^{*}$ otherwise. If the seller does not accept credit, then $q=\omega^{-1}(z)$ if $z \leq \omega\left(q^{*}\right)$ and $q=q^{*}$ otherwise. Hence in both cases, the buyer obtains the first-best $q^{*}$ and pays an amount exactly equal to $\omega\left(q^{*}\right)$ if $\omega\left(q^{*}\right) \leq z+\bar{b}$. Otherwise, the buyer just pays with $z+\bar{b}$ and gets in exchange $\omega^{-1}(z+\bar{b})$ if the seller accepts credit or $\omega^{-1}(z)$ if the seller only takes cash. The function $\omega(\cdot)$ therefore specifies the payment required to obtain either $q$ or $q^{c}$.

Proportional bargaining guarantees the concavity of the DM value functions and implies that each agent's surplus increases monotonically with the match surplus. These properties generally do not hold for Nash bargaining. Under Nash bargaining, the buyer's value function in the DM is

$$
V^{b}(z)=\sigma(1-\Lambda) \ell(z)+\sigma \Lambda \ell(z+\bar{b})+z+W^{b}(0,0)
$$

where $\ell(\cdot)=u[q(\cdot)]-\omega[q(\cdot)]$ is the buyer's DM surplus and

$$
\omega[q(\cdot)]=\frac{\theta u^{\prime}[q(\cdot)] c[q(\cdot)]+(1-\theta) c^{\prime}[q(\cdot)] u[q(\cdot)]}{\theta u^{\prime}[q(\cdot)]+(1-\theta) c^{\prime}[q(\cdot)]}
$$

is the transfer of wealth the buyer makes to the seller. In contrast with the proportional solution, the Nash solution implies that $\ell(\cdot)=u[q(\cdot)]-\omega[q(\cdot)]$ is non-monotonic in $q$ over $\left[0, q^{*}\right]$ and decreasing near $q^{*}$. As a result, the buyer's surplus reaches a maximum at some $\bar{q}<q^{*}$ where $\bar{q}$ is the value of $q$ such that $u^{\prime}(\bar{q})=\omega^{\prime}(\bar{q})$.

Accordingly, the choice of real balances for a buyer with access to credit, $z \geq 0$, solves

$$
-i+\sigma(1-\Lambda) \ell^{\prime}(z)+\sigma \Lambda \ell^{\prime}(z+\bar{b}) \leq 0,
$$

where (34) is satisfied with equality if $z>0$ and

$$
\ell^{\prime}(\cdot) \equiv \frac{u^{\prime}[q(\cdot)]}{\omega^{\prime}[q(\cdot)]}-1
$$

Similarly, the choice of real balances for a buyer who defaults and hence loses access to credit, $\widetilde{z} \geq 0$, solves

$$
-i+\sigma \ell^{\prime}(\widetilde{z}) \leq 0
$$

where (35) is satisfied with equality if $\widetilde{z}>0$. We will later use the fact that $\ell^{\prime}(0)=\infty$ under Nash bargaining implies (34) and (35) hold at equality for any $i \geq 0$ (recall that Kalai bargaining implies $\ell^{\prime}(0)=\frac{\theta}{1-\theta}$, which places a finite bound on inflation such that money is valued). 
Finally, the equilibrium debt limit, $\bar{b}$, solves

$$
r \bar{b}=\max _{z \geq 0}\{-i z+\sigma[(1-\Lambda) \ell(z)+\Lambda \ell(z+\bar{b})]\}-\max _{\widetilde{z} \geq 0}\{-i \widetilde{z}+\sigma \ell(\widetilde{z})\} \equiv \Omega(\bar{b}) .
$$

\section{Endogenous Credit Limits}

As before, we consider first the model with exogenous acceptability of credit since we will need to work out the equilibrium for any given $\Lambda$ whether or not record-keeping is endogenous. We begin by establishing some key properties of the flow cost of default given by (36). Define $\bar{b}_{1} \equiv \omega\left(q^{*}\right)$ and $\bar{z}$ as the real balances that solve

$$
i=\sigma(1-\Lambda) \ell^{\prime}(\bar{z}) .
$$

Lemma 2' below summarizes some key properties of the flow cost of default given the value of money, and is the analog of Lemma 2 from the main text.

Lemma 2'. Given $\Lambda \in(0,1)$ and $i>0$, the correspondence $\Omega(\bar{b})$ has the following properties.

1. When money is not valued, $\left.\Omega(\bar{b})\right|_{\phi=0}$ is such that

(a) $\left.\Omega(0)\right|_{\phi=0}=0$

(b) $\left.\Omega^{\prime}(0)\right|_{\phi=0}=\sigma \Lambda \ell^{\prime}(0)=\infty$,

(c) $\left.\Omega^{\prime}(\bar{b})\right|_{\phi=0}=0$ if $\bar{b} \geq \bar{b}_{1}$.

2. When money is valued, $\left.\Omega(\bar{b})\right|_{\phi>0}$ is such that

(a) $\left.\Omega(0)\right|_{\phi>0}=0$

(b) $\left.\Omega^{\prime}(0)\right|_{\phi>0}=i \Lambda>0$,

(c) $\left.\Omega^{\prime}(\bar{b})\right|_{\phi>0}=0$ if $\bar{b} \geq \bar{b}_{1}-\bar{z}$.

A difference between Lemma 2 and Lemma 2' is that we cannot guarantee the buyer's surplus function and hence the flow cost of default is concave in $\bar{b}$ for all values of $\theta>0$. However since $\left.\Omega(0)\right|_{\phi=0}=0$ and $\left.\Omega^{\prime}(0)\right|_{\phi=0}=\infty$, a sufficient condition for a pure credit equilibrium is $r<\sigma \Lambda \ell^{\prime}(0)$, which is always satisfied with Nash bargaining since $\ell^{\prime}(0)=\infty$. This means we can find at least one fixed point of (36) when money is not valued. It is also possible to have multiple pure credit equilibria, though we can guarantee uniqueness if parameters are such that $\left.\Omega(\bar{b})\right|_{\phi=0}$ is concave, for instance when $\theta \approx 1$. Similarly, since the necessary and sufficient condition for a pure monetary equilibrium is $i<\sigma \ell^{\prime}(0)$, the upper bound on $i$ such that monetary equilibrium exists is infinite. 
To summarize, there exists a pure monetary equilibrium for any $i \geq 0$ and a pure credit equilibrium for any $\Lambda \in(0,1]$. Unlike with Kalai bargaining, there is no longer a fundamentalsdriven non-monetary equilibrium or a fundamentals-driven equilibrium without credit- though there still always exists a beliefs-driven or self fulfilling non-monetary equilibrium and equilibrium without credit for any combination of parameters.

We now check the conditions for a money and credit equilibrium. First, given money is valued, credit is feasible if $r<i \Lambda$, or $i>\frac{r}{\Lambda} \equiv \underline{i}$. Second, given a debt limit, money is valued if and only if

$$
i<\sigma(1-\Lambda) \ell^{\prime}(0)+\sigma \Lambda \ell^{\prime}[\bar{b}(i, \Lambda)]
$$

or $i<\widetilde{i}$ where $\widetilde{i}$ solves

$$
\widetilde{i}=\sigma(1-\Lambda) \ell^{\prime}(0)+\sigma \Lambda \ell^{\prime}[\bar{b}(\widetilde{i}, \Lambda)] .
$$

When $\Lambda \in(0,1), \ell^{\prime}(0)=\infty$ implies (37) is always satisfied, and when $\Lambda=1, \widetilde{i}=\underline{i}=r$. Consequently, a money and credit equilibrium exists under Nash bargaining if $\Lambda \in(0,1)$ and $i>\frac{r}{\Lambda}$ or if $\Lambda=1$ and $i=r$. As in our model with Kalai bargaining, perfect monitoring $(\Lambda=1)$ implies money is not essential given what can be achieved with credit.

Proposition 1' and Proposition 2' below summarize our main results on the existence of equilibria and coexistence of money and credit with generalized Nash bargaining.

Proposition 1'. Given $\Lambda \in(0,1]$ and $i>0$, the following outcomes are possible.

1. When $\Lambda \in(0,1)$, a money and credit equilibrium exists if and only if $i>\frac{r}{\Lambda}$, and coexists with a pure monetary equilibrium, a pure credit equilibrium, and a non-monetary equilibrium without credit.

2. When $\Lambda=1$, a money and credit equilibrium does not exist for any $i \neq r$, but there exists a pure monetary equilibrium, a pure credit equilibrium, and a non-monetary equilibrium without credit. If $i=r$, there is a continuum of equilibria where the debt limit is indeterminate.

Proposition 2'. Given $\Lambda \in(0,1]$ and $i>0$, equilibrium can either be (i) a pure monetary equilibrium, a pure credit equilibrium, and autarky; or (ii) a pure monetary equilibrium, a pure credit equilibrium, a money and credit equilibrium, and autarky if $\Lambda<1$ and $i>\frac{r}{\Lambda}$ or $\Lambda=1$ and $i=r$.

\section{Endogenous Record-Keeping}

We now consider the model where the acceptability of credit is endogenous. The analysis when terms of trade are determined with Nash bargaining is very similar to the analysis in the main text, 
except the seller's problem is now given by

$$
\max \{-\kappa+\sigma[\omega[q(z+\bar{b})]-c[q(z+\bar{b})]], \sigma[\omega[q(z)]-c[q(z)]]\}
$$

Accordingly, the expected benefit of investing, $\bar{\kappa}$, is now given by

$$
\bar{\kappa} \equiv \sigma\{\omega[q(z+\bar{b})]-c[q(z+\bar{b})]\}-\sigma\{\omega[q(z)]-c[q(z)]\}
$$

Given $\bar{\kappa}$, an individual seller's decision problem is summarized by (26) while aggregate decisions are summarized by (27).

All our main findings with endogenous record-keeping largely go through with Nash bargaining and are very similar to the results reported in the main text. 